\title{
Interpersonal stress regulation and the development of anxiety disorders: an attachment-based developmental framework
}

\author{
Tobias Nolte ${ }^{1,2}{ }^{\dagger}$, Jo Guiney ${ }^{3 \dagger}$, Peter Fonagy ${ }^{1,2}$, Linda C. Mayes ${ }^{2,4}$ and Patrick Luyten ${ }^{1,5}$ \\ ${ }^{1}$ Research Department of Clinical, Educational and Health Psychology, University College London, London, UK \\ ${ }^{2}$ Developmental Neuroscience Unit, Anna Freud Centre, University College London, London, UK \\ ${ }^{3}$ Royal Holloway, University of London, London, UK \\ ${ }^{4}$ Yale Child Study Center, Yale University, New Haven, CT, USA \\ ${ }^{5}$ Department of Psychology, University of Leuven, Leuven, Belgium
}

\section{Edited by:}

Luke R. Johnson, Uniformed Services University of the Health Sciences,

USA

\section{Reviewed by:}

René Hurlemann, University of Bonn Germany

Kwang Choi, Uniformed Services University of the Health Sciences, USA

\section{*Correspondence:}

Tobias Nolte, Anna Freud Centre, 12 Maresfield Gardens, London NW3 5SU, UK.

e-mail: tobias.nolte@annafreud.org

${ }^{\dagger}$ Tobias Nolte and Jo Guiney share joint first authorship.
Anxiety disorders represent a common but often debilitating form of psychopathology in both children and adults. While there is a growing understanding of the etiology and maintenance of these disorders across various research domains, only recently have integrative accounts been proposed. While classical attachment history has been a traditional core construct in psychological models of anxiety, contemporary attachment theory has the potential to integrate neurobiological and behavioral findings within a multidisciplinary developmental framework. The current paper proposes a modern attachment theory-based developmental model grounded in relevant literature from multiple disciplines including social neuroscience, genetics, neuroendocrinology, and the study of family factors involved in the development of anxiety disorders. Recent accounts of stress regulation have highlighted the interplay between stress, anxiety, and activation of the attachment system. This interplay directly affects the development of social-cognitive and mentalizing capacities that are acquired in the interpersonal context of early attachment relationships. Early attachment experiences are conceptualized as the key organizer of a complex interplay between genetic, environmental, and epigenetic contributions to the development of anxiety disorders - a multifactorial etiology resulting from dysfunctional co-regulation of fear and stress states. These risk-conferring processes are characterized by hyperactivation strategies in the face of anxiety. The cumulative allostatic load and subsequent "wear and tear" effects associated with hyperactivation strategies converge on the neural pathways of anxiety and stress. Attachment experiences further influence the development of anxiety as potential moderators of risk factors, differentially impacting on genetic vulnerability and relevant neurobiological pathways. Implications for further research and potential treatments are outlined.

Keywords: stress, anxiety, anxiety disorders, mentalization, attachment, hyperactivation, allostasis

\section{INTRODUCTION}

Contemporary perspectives in developmental psychopathology conceptualize attachment relationships as part of a complex network of epigenetic factors which interact to confer risk of or resilience to the development of stress-related psychopathology (e.g., Fonagy and Luyten, 2009; van Ijzendoorn et al., 2010; Luyten et al., submitted for publication). This paper presents a model of the influence of attachment relationships on the development of stress regulation strategies and discusses the role those relationships play in the development and maintenance of anxiety disorders, particularly the neurobiological alterations that underpin them.

Anxiety disorders are characterized by a pronounced dysfunction of systems underpinning stress regulation and fear responses (Mineka and Zinbarg, 1996; Rosen and Schulkin, 1998). It has been hypothesized that individual styles of threat response and stress regulation develop within the context of early caregiving experiences (Luyten et al., submitted for publication). These styles are thought to persist throughout the life cycle, providing a theoretical framework for linking early attachment to later anxiety disorders (Gunnar and Quevedo, 2007; Sbarra and Hazan, 2008). From this perspective, stressful experiences, physiological stress regulation, and attachment relationships are inherently linked, as the activation of the attachment system invariably follows the early stages of detecting and processing fear-related cues, stressresponses, and states of anxiety (e.g., Murgatroyd and Spengler, 2011; Luyten et al., submitted for publication). Specifically, the biologically based activation of a child's attachment system following distress entails coordinated behaviors that aim to address the stress response by eliciting the attention, and by ensuring the proximity and protection of attachment figures. When effective, this process leads to a co-regulation of the child's distress (Sbarra 
and Hazan, 2008). Hence, at least some of the mechanisms by which stress-regulatory strategies are acquired are inherently interpersonal in nature and, it is argued, these strategies persist into adulthood and are relevant for the understanding of the nature and development of anxiety disorders. In this paper we review evidence from prospective human behavioral studies showing that a history of insecure-anxious infant-caregiver attachment, characterized by an excessive intensification of distress signals to elicit caregiver responsiveness and maintain proximity, is a risk factor for developing anxiety disorders in middle childhood and adolescence (Bosquet and Egeland, 2006), even when maternal anxiety and temperament are controlled for (Warren et al., 1997). Based on these and similar studies, we propose a theoretical model arguing that the characteristic up-regulation of stress reactivity observed in individuals classified as insecure-anxious may be an important risk factor for the development of anxiety disorders (Vasey and Dadds, 2001; Muris et al., 2003; Shaw and Dallos, 2005; Lee and Hankin, 2009). Thus, we argue that an understanding of the normative and pathological development of stress-regulatory systems within an attachment context is likely to be important for elucidating the etiology and may also directly inform the treatment of anxiety disorders.

In this context, the multiple levels of the stress response must be taken into account. Research into stress and anxiety disorders in past decades has tended to consider factors such as behavioral, genetic, or physiological phenomena in isolation. Recently, however, more comprehensive developmental formulations have been proposed that are notable for their integration of findings from genetic and social neuroscience research in adults (e.g., Heim and Nemeroff, 2001; Pine, 2007; Martin et al., 2009). With convergent findings in adult research indicating that neurobiological underpinnings are broadly shared by most anxiety disorders (Martin et al., 2009; Etkin, 2010) there have been calls for a comprehensive integration of research findings from multiple levels of analysis utilizing a developmental perspective (e.g., Gross and Hen, 2004; Murray et al., 2009; Cicchetti, 2010).

The developmental model proposed in this paper attempts to respond to such calls by highlighting, within an integrative account, the role of early attachment relationships. In this framework, individual differences in parental stress regulation are conceptualized as impacting upon the stress regulation strategies developed by the child. This process is proposed to confer both risk of or resilience to the development of anxiety-related psychopathology. More specifically, we propose that stress- and fear-triggered co-regulatory processes between parent and child within the attachment relationship are evolutionarily vital and neurobiologically pre-wired adaptations to the child's specific early caregiving environment. These early adaptations are preserved to ensure the superior adaptation of the organism to likely environmental challenges over the course of the life cycle.

Behavioral and physiological aspects of stress regulation have been comprehensively described in adults (McEwen, 2007; Chrousos, 2009), and this is increasingly the case in children (Gunnar and Quevedo, 2007). However, research focusing on the intergenerational transmission of dysfunctional stress regulation, and the role of this transmission in the subsequent emergence of anxiety disorders, is relatively underdeveloped. Stress in a child's early caregiving environment has been linked to lasting adverse effects on both physiological and psychological domains of development (National Scientific Council on the Developing Child, 2005; Gunnar and Quevedo, 2007; Nugent et al., 2011). These findings are congruent with population-representative studies that have shown that early adversity, and particularly attachment-related trauma, is related to increased risk for anxiety disorders throughout the life span (Green et al., 2010; Luyten et al., submitted for publication). For example, early adversity, such as maltreatment and neglect, have been consistently shown to lead to chronic alterations in the function of the hypothalamic-pituitary-adrenal (HPA) axis, both at a the level of basal activity and in response to stress (De Bellis et al., 1999; Heim and Nemeroff, 2001; Lupien et al., 2009). Hyperresponsiveness of this system is also implicated in the anxiety disorders (Kallen et al., 2008; Etkin, 2010). Further theory-driven research is required to link the interpersonal mechanisms involved in the emergence of childhood anxiety problems with studies of the heterogeneity in stress responsivity (Luyten et al., submitted for publication). This paper is an attempt to provide a theoretical framework for such research and outlines implications for intervention strategies. While the psychopharmacological treatment of anxiety is beyond the scope of this paper, its central role in intervention is acknowledged. Rather, the model presented here suggests how attachment-based interventions may enhance a range of other treatments, including pharmacological approaches.

\section{PAPER OUTLINE}

This paper covers three literatures. We begin by reviewing literature on anxiety disorders from the perspective of a number of disciplines. Next, an account of the role of attachment in the development of both normative and aberrant stress regulation is explicated. Finally, an integrative developmental model for the etiology of anxiety disorders is proposed based on constructs drawn from the interface of modern attachment theory and neuroscience.

Differences in the presentations of the various anxiety disorders may reflect variations in etiological pathways, but we suggest that the unregulated fear responses and subsequent hyperactivation of the attachment system is shared by these diagnostic entities. For this reason, the focus of this paper is on the anxiety disorders as a group. This is in line with studies concerning a tripartite model showing that anxiety disorders empirically cluster together, separate from depression for instance (Clark and Watson, 1991; De Bolle and De Fruyt, 2010; Luyten and Blatt, 2011), and with findings from recent studies based upon multivariate statistical analyses indicating that anxiety disorders can be hierarchically ordered as part of a spectrum of internalizing disorders (Krueger et al., 2007).

\section{ANXIETY DISORDERS}

While fear is an evolutionarily preserved response to environmental threat and enables appropriate defensive behaviors such as escape and avoidance (Rosen and Schulkin, 1998) the excessive fear responses that characterize pathological anxiety have been conceptualized as a dysfunctional variant of these originally adaptive processes. (Mineka and Zinbarg, 1996; LaBar and Phelps, 2005; Shin and Liberzon, 2009). While resulting symptomatology can 
range from the persistent and non-specific apprehension in Generalized Anxiety Disorder to the overwhelming terror present in Panic Disorder, the presence of fear and stress states is common to these presentations (Craske et al., 2009).

\section{PREVALENCE}

Lifetime prevalence data consistently shows anxiety disorders to be the most commonly occurring class of mental disorders (e.g., Lépine, 2002; Kessler and Wang, 2008), usually with a chronicrecurrent course (Kessler et al., 2010). Several population studies attest to the high prevalence of anxiety disorders occurring before adulthood (Breton et al., 1999; Canino et al., 2004) and though estimates vary, at any given time approximately $2.5-5 \%$ of children and adolescents meet criteria for an anxiety disorder (Ford et al., 2003). Evidence from longitudinal studies suggests that the life-interference associated with shyness and anxiety disorders in childhood persists into early adulthood (Caspi et al., 1996; Last et al., 1996), while studies demonstrating the longitudinal stability of features predicting anxiety disorders from childhood to adolescence (Bittner et al., 2007) and from adolescence to early adulthood (Pine et al., 1998) emphasize the importance of a developmental approach.

\section{COMORBIDITY}

Estimates suggest that $40-60 \%$ of children and adolescents with a specific anxiety disorder meet criteria for at least one other anxiety disorder (Benjamin et al., 1990; Kendall et al., 2001). Such a high level of comorbidity within the anxiety disorders likely reflects both shared risk factors and common underlying fear processes maintaining the presentation (Rapee et al., 2009).

Population studies also indicate high levels of comorbidity with other psychiatric disorders (Angold et al., 1999), with significant associations existing between anxiety disorders and the subsequent onset of other psychiatric (Beesdo et al., 2007) and substance use (e.g., Zimmerman and Chelminski, 2003) disorders. However, the most striking and consistent finding of population studies is the marked comorbidity of anxiety disorders and depression. It is estimated that anxious children are between 8 and 29 times more at risk of developing subsequent depression than non-anxious children (Angold et al., 1999; Costello et al., 2003; Ford et al., 2003).

Given the early onset of anxiety disorders, they commonly represent the temporally primary disorder in comorbid profiles. It is on this basis that some commentators have suggested that early interventions to treat anxiety disorders might attenuate risk for the onset, persistence, or severity of secondary disorders such as depression and substance abuse (Wittchen et al., 2000; Kessler, 2004) underscoring the value of developmental accounts of etiology and course.

\section{FACTORS CONTRIBUTING TO THE DEVELOPMENT OF ANXIETY DISORDERS}

Before outlining the key role of the attachment relationship in the development of stress-regulatory processes in the face of threat and anxiety, a review of the critical factors that have been implicated in the development of anxiety disorders is presented. These factors have been investigated across multiple disciplines and are examined in turn.
GENETIC INFLUENCES ON THE DEVELOPMENT OF ANXIETY DISORDERS A growing body of research supports the familial aggregation of anxiety disorders (Hettema et al., 2001) with findings consistently demonstrating that children with anxiety disorders are more likely to have a parent with an anxiety disorder (Last et al., 1987, 1996; Cooper et al., 2006; Schreier et al., 2008).

Twin studies have allowed for estimates of the actual contribution of genetic factors to the pathogenesis, or heritability, of anxiety disorders and consistently report a genetic influence of a moderate magnitude (Thapar and McGuffin, 1995; Hettema et al., 2001, 2005; Ehringer et al., 2006; Gregory and Eley, 2007). In considering transdiagnostic overlap of anxiety psychopathology accounted for by genetic and environmental influences, estimates have varied according to the form of anxiety investigated (Eley et al., 2003, 2010; Ehringer et al., 2006), with Obsessive-Compulsive and Shyness/Inhibition behaviors most consistently indicated as highly heritable and Separation Anxiety as more strongly influenced by shared environmental factors.

This evidence for phenotypic and genetic overlap in the various behaviors associated with the anxiety disorders has provided the basis for their common consideration as a group. However, while the differentiation in genetic contributions can partially account for the heterogeneity of presentations in the anxiety disorders, environmental influences remain substantial in each diagnostic entity. Defining the nature of the early experiences that may interact with genetic risk factors to produce anxiety-related phenotypes is therefore crucial (Norrholm and Ressler, 2009).

Furthermore, it has been argued that genetic and environmental factors may be more or less influential depending on a subject's developmental stage, and that factors relating to the primary caregiver will account for more variance during early to middle childhood, when parents exert the strongest influence on their children (Rapee and Spence, 2004). In line with this, variations in a polymorphism of the serotonin transporter gene have been associated with anxiety sensitivity, but only in the presence of childhood maltreatment (Stein et al., 2008).

\section{TEMPERAMENT AND ANXIETY DISORDERS}

Various nosologies of temperament have described a style in infancy characterized by inhibition, shyness, withdrawal, and distress in response to novelty, and a tendency to stay within close proximity to attachment figures (Windle and Lerner, 1986; Kagan et al., 1988; Hirshfeld et al., 1992; Sanson et al., 1996; Chorpita and Barlow, 1998). As a result, although studies examining childhood anxiety have utilized different classification criteria for temperament, nearly all employ measures of behavioral inhibition (BI) and proneness to distress reactions when faced with novelty. For purposes of clarity and because it is the most commonly used term across disciplines, we refer to this temperament style as BI.

It has been suggested that BI might serve as a potential endophenotype in research into anxiety disorders (Smoller et al., 2005; Norrholm and Ressler, 2009). Indeed, associations have been found between BI in children and anxiety disorders in their parents (Biederman et al., 1993; Rickman and Davidson, 1994), and longitudinal studies have shown that BI in childhood predicts later anxiety disorders (Hirshfeld et al., 1992; Turner et al., 1996; Prior et al., 2000). 
Although BI features have much in common with those observed in children with an insecure-anxious attachment classification (Calkins and Fox, 1992), meta-analyses investigating this overlap have indicated that individual differences in attachment style cannot be explained by temperament constructs (Vaughn and Bost, 1999). Rather, contemporary accounts posit that temperament and attachment are distinct but interacting influences on the child's development (for a review, see Vaughn et al., 2008).

In relation to the model proposed in the current paper, a BI temperament style is conceptualized as one potential risk for the development of anxiety disorders (Rapee and Coplan, 2010), and a factor interacting with an individual's attachment status.

\section{ENDOCRINOLOGICAL, NEURAL, AND COGNITIVE MEDIATORS OF STRESS REGULATION AND ANXIETY DISORDERS \\ HPA-axis sensitivity programming}

The concept of developmental programming (Andrews and Matthews, 2004; Meaney et al., 2007; Seckl, 2008) has been proposed in response to a large body of research demonstrating that environmental cues at sensitive periods of development can result in permanent alterations in the functioning of the HPAaxis (Matthews, 2002; De Kloet et al., 2005; Oitzl et al., 2010). Preclinical and clinical evidence suggests that this programming is relevant to an understanding of the etiology of anxiety disorders in humans (Heim et al., 2004, 2008; Capitanio et al., 2005) with a growing number of studies in human samples indicating that stressors within the early caregiving environment are associated with alterations in the functioning of the HPA-axis and an increased risk of heightened anxiety and psychopathology later in life (Graham et al., 1999; Rinne et al., 2002; Heim et al., 2008).

It has been suggested that maternal care plays a key mediating role in the regulation of the HPA-axis in offspring (e.g., Gunnar and Donzella, 2002; Taylor et al., 2011). Adequate care has been associated with reduced cortisol levels and an attenuation of HPA-axis responsiveness in children, together with a greater cortisol recovery post-stress (Albers et al., 2008). These findings are highly pertinent to the attachment framework applied in the current paper as they underscore the interpersonal nature of stress regulation. The regulation of the HPA-axis as a primary function of the attachment relationship is a key component of the current model.

The effects of prenatal anxiety on HPA-axis function. A number of studies have demonstrated associations of antenatal maternal anxiety with cognitive, behavioral, and emotional problems in the child (Van den Bergh and Marcoen, 2004; O'Connor et al., 2005; Bergman et al., 2010). In investigating potential physiological mediators underpinning the sequelae of prenatal maternal anxiety, attention has largely focused on its effects on the HPAaxis of the offspring. Based on the evidence for overactive and dysregulated HPA axes in the offspring of prenatally stressed animals (Weinstock et al., 1992; McCormick et al., 1995; Huizink et al., 2004), it has been hypothesized that exposure to anxiety and stress in the prenatal environment may result in susceptibility to psychopathology, such as anxiety disorders and/or depression, in humans (Van den Bergh et al., 2008).
In a recent study examining outcomes associated with prenatal stress and the impact of attachment, Bergman et al. (2010) documented that levels of maternal prenatal cortisol measured in amniotic fluid were linked with impaired cognitive development in children. However, mother-infant attachment moderated these in utero effects: the negative outcome only held true when early caregiving was characterized by attachment insecurity. Further, it has been shown that prenatal stress is associated with reduced hippocampal volume only when combined with inadequate levels of post-natal care from the mother (Buss et al., 2007).

Taken together, this body of research suggests that although prenatal stress can confer risk for anxiety disorders through altering the set-point of the HPA-axis, this risk can be attenuated by the early caregiving environment and attachment experiences in particular.

\section{Neural basis of anxiety}

Current understanding of fear conditioning and threat responses at a neural level derives mainly from animal research and subsequent translational efforts that apply these animal models to study fear and anxiety processes in normal human populations (LeDoux, 2000; Schiller et al., 2010; Schiller and Phelps, 2011). Phenomenologically, the arousal and avoidance responses of subjects with anxiety disorders resemble the reactions of normal subjects to conditioned fear cues (Grillon, 2002). Crucially, both groups of subjects display the same accompanying changes in the neural substrates that coordinate their defensive responses to threats. Responses in humans with anxiety disorders are therefore likely to represent extreme manifestations of the normal, context-appropriate responses to stress and fear that have proven evolutionarily successful (Rosen and Schulkin, 1998; Gray and McNaughton, 2000; Rauch et al., 2000; Shekhar et al., 2005).

Any account of the neurobiological underpinnings of anxiety disorders should therefore be based on an understanding of the neural circuitry underlying normal processing of fear and subsequent normative regulatory mechanisms. Neuroscientific evidence has converged to delineate a well-established limbic-medial prefrontal system comprising three functionally interacting groups of brain structures (Etkin and Wager, 2007; Kober et al., 2008; Martin et al., 2009; Etkin, 2010). The complex interaction of these structures is summarized here in brief.

First, detection of and early response to fear cues and/or negative emotional stimuli occur within the phylogenetically ancient limbic structures of the amygdala and insula. The result is a first integration of sensory, affective, and interoceptive processes (see Etkin and Wager, 2007 for a quantitative meta-analysis of the involvement of these areas in anxiety-relevant emotional processing). In turn, these regions initiate and modulate activity in several target structures (including the hypothalamus, periaqueductal gray, sensory cortices, and the hippocampus) to carry out coordinated physiological and behavioral responses. The hippocampus exerts an important regulatory function via negative feedback to the HPA-axis (Pruessner et al., 2010). Hippocampal volume and neurogenesis have been implicated in stress resilience and in the stress sensitivity associated with anxiety disorders (Lupien et al., 2009; Roozendaal et al., 2009). 
Subsequent appraisal of the registered fear cues occurs in the dorsal anterior cingulate and dorsomedial prefrontal cortices. This detailed evaluation of the emotional stimulus has a potential gate-keeping function that may admit the stimulus to conscious awareness and may trigger the context-dependent inhibition or enhancement of limbic activation. Finally, the engagement of a third part of the circuit (involving rostral subregions of the anterior cingulate and ventromedial prefrontal cortex) is responsible for top-down-regulation of negative emotions and limbic processing. Furthermore, executive regions within the lateral prefrontal cortex activate medial prefrontal regulation of emotion processing.

The complexity of the interdependent functions of the regions within the limbic prefrontal circuit suggests that anxiety processing and responses do not rely on specific areas that perform unique functions. Rather, anxiety processing and response should be conceived of as emergent functions of interacting brain areas (Morgane et al., 2005). Furthermore, these circuits are under the modulatory influence of several other neural systems and neuropeptides (e.g., Mathew et al., 2008; Joels and Baram, 2009). Oxytocin, in particular, has been studied widely during the last decade (Insel, 2010). Its crucial role in mediating attachment as well as its influence on the neural circuits underpinning anxiety are discussed further below.

Accruing evidence suggests that the neural correlates of anxiety disorders involve an abnormally elevated activation pattern in the limbic structures. This leads to hypoactivation in prefrontal regions aimed at normalizing limbic response, and thus to regulatory failures. In a normal population, the neuronal processing of participants who scored higher on an anxiety measure, already appears to involve, via activation of the basolateral amygdala, a more generalized dysregulation and distorted detection of negative affect (Etkin et al., 2004; Campbell-Sills et al., 2010). Studying the regulation of negative affect in a sample of older adults, Urry et al. (2006) reported an inverse coupling of amygdala and ventromedial prefrontal cortex activation. This association also predicted diurnal cortisol secretion.

These findings, in particular the role of increased amygdala activation provoked by anxiety-producing unpredictable or ambiguous stimuli, are indicative of "hyperarousal and hypervigilance" (Etkin et al., 2004). These states are similar to behavioral responses found in anxiety disorders. This is of particular relevance, since most anxiety disorders are characterized by intolerance of uncertainty or ambiguity (Holaway et al., 2006; Boelen and Reijntjes, 2009) and a bias toward negative interpretations of ambiguous cues (Bishop, 2007). Additionally, success in interpreting negative stimuli as less threatening is associated with increased PFC and decreased amygdalar activity (Bishop, 2007) implying the central role of interpretation of experience. These processes reflecting normal social cognition or mentalizing capacities will be explained in detail below. Investigating the structural integrity of the amygdala-prefrontal pathway with diffusion tensor imaging, Kim and Whalen (2009) found evidence for an inverse correlation with participants' trait anxiety levels. This linked higher pathway strength with lower anxiety. In addition, studies on the resting brain showed that the level of anxiety can dissociate ventromedial prefrontal cortex functional connectivity with the amygdala, resulting in compromised interactions between these two brain regions (Kim et al., 2011). This may partly explain the failure to downregulate anxiety-provoked stress states, especially when these occur in interpersonal contexts as our model will show.

Taking these findings together, it appears likely that the prefrontal-amygdala circuit mediates basic mechanisms involved in human anxiety. These mechanisms include: "attention to threat, interpretation of stimuli, and acquisition and extinction of conditioned fear" (Bishop, 2007). Ultimately, this mediation can lead to a pathological bias in favor of negative representations of external and internal cues and to a failure to activate alternative non-threatening representations.

Evidence from recent functional neuroimaging research in clinical populations suggests commonalities in the functional anatomy underpinning most anxiety disorders (van den Heuvel et al., 2005; Pine, 2007; Ressler and Mayberg, 2007; Martin et al., 2009; Etkin, 2010; Shin and Liberzon, 2009 for review of the overlap with neural circuits of depression). Additionally, there are disorder-specific features in pathologies such as obsessive-compulsive disorder (Martin et al., 2009; Etkin, 2010). In the most comprehensive meta-analysis on negative emotional processing, Etkin and Wager (2007) demonstrated that limbic hyperactivation in patients with PTSD, social anxiety, or specific phobia was similar to anxiety experimentally induced through fear conditioning in healthy individuals. The finding that amygdala and insula hyperactivation is common to all three anxiety disorders is suggestive of patients' "excessive engagement of fear- or negative emotion-related circuitry" and reflects a neural phenotype of anxiety (Etkin and Wager, 2007) as well as of alterations in interoceptive processing of anxiety-induced affect (Paulus and Stein, 2006; Stein et al., 2007). Future research, however, is needed to address whether these functional perturbations represent acquired characteristics of anxiety disorders or reflect vulnerability factors that precede the onset of psychopathology. A growing body of developmental research investigates neuro-structural correlates of exposure to stressors in the early environment, finding for example, corticostriatal-limbic gray matter reductions in adolescents reporting maltreatment in childhood (Edmiston et al., in press) and decreases in corpus callosum volume in maltreated children and adolescents compared to their non-maltreated peers (Jackowski et al., 2008). Preliminary evidence suggests such structural differences in response to early life stress might be mediated by gender (Teicher et al., 2004).

\section{Attentional bias to threat}

Cognitive accounts have suggested that development of an attentional bias to threatening stimuli is both a mechanism by which early experience shapes an individual's stress responsivity and a risk factor for the development of anxiety disorders (MacLeod et al., 2002). It is now well-established that attentional biases are present in individuals diagnosed with a range of anxiety disorders (Bar-Haim et al., 2007) as indexed by heightened and sustained vigilance for visual stimuli conveying threat (Mogg and Bradley, 2002). Attentional biases have also been associated with heightened HPA-axis activity (Ellenbogen et al., 2002; Roelofs et al., 2007) providing a basis for cognitive-biological accounts of mood disorders (Beck, 2008). Furthermore, a genetic mechanism for attentional biases has emerged through its association with variations in the serotonin transporter gene (Perez-Edgar et al., 2010). 
It has, however, been proposed that a child who is genetically vulnerable to anxiety may or may not develop an attentional bias toward threat depending upon the early caregiving environment (Fox et al., 2007). This research demonstrated that caregivers who highlight or identify negative events in their child's environment are contributing to the child's own development of a negative bias. It is interesting therefore that recognition and modification of attentional biases has been a central aspect of Cognitive Behavioral approaches to the treatment of the anxiety disorders (e.g., Beck, 1976; Beck and Emery, 1985).

\section{ENVIRONMENTAL INFLUENCES \\ Early adversity}

Although there is evidence indicating that children diagnosed with an anxiety disorders experience more negative events preceding diagnosis when compared to non-anxious controls (Goodyer et al., 1988; Phillips et al., 2005), such findings are called into question by studies indicating reciprocal influences. For example, it has been demonstrated that childhood anxiety predicts the occurrence of subsequent negative events (Swearingen and Cohen, 1985). Similarly, longitudinal research by Kim et al. (2003) demonstrated that internalizing problems such as anxiety and depression followed, but were also followed by, negative life events.

The processes whereby adverse events lead to the development of an anxiety disorder are therefore likely to be mediated by multiple factors, including attachment experiences (Cicchetti and Rogosch, 1997). Studies have in fact demonstrated that, in the presence of risk factors such as early adversity (Carlson and Sroufe, 1995) and stressful events (Heinrichs et al., 2003; Powers et al., 2006), secure attachment can act as a protective factor moderating the potential for development of psychopathology via the impact on stress regulation (Gunnar et al., 1996; Nachmias et al., 1996).

\section{Parenting influences}

Modeling and information transfer. A child's observation of anxiety in others has been proposed as a route for the intergenerational transmission of anxiety disorders (Mineka, 1985). Such learning-theory accounts posit that caregiver modeling allows the child to vicariously acquire behaviors, and that this is likely to be evolutionarily advantageous because it prepares the child for environmental challenges without exposing him to direct threat (Mineka, 1988). For example, in a sample of mothers without anxiety disorders and their 15 to 20-month-old infants, fear modeling by the mothers was found to be associated with the subsequent fear responses of the infants (Gerull and Rapee, 2002). In a more recent longitudinal study comparing mothers with and without an anxiety disorder (Murray et al., 2008), the level of anxiety expressed by the mother toward a stranger in front of their 10-month-old infant predicted the infant's subsequent avoidance of the same stranger at 14 months.

Research examining features of child-parent discussions has shown that anxious mothers are more likely to make comments of a catastrophic nature to their children (Whaley et al., 1999; Moore et al., 2004) and less likely to refer to positive emotions (Suveg et al., 2008). Further, compared to discussions in non-clinical families, discussions regarding ambiguous situations within families of anxious children appear to be characterized by reciprocal reinforcement of comments regarding risk and have been shown to magnify the extent of a child's anxiety and avoidance behavior in subsequent situations (Barrett et al., 1996).

This body of literature links parental behavior to anxiety in children via parental displays of anxiety or verbal behaviors emphasizing threat in the environment. These instances of "modeling" may also in part be seen as failures of the attachment system since the parent does not (or is unable to) show appropriate caregiving behavior within a stressful situation, and thus fails to effectively co-regulate the child's stress. Rather, the caregiver models to the child their own strategies for evaluating and responding to threat.

Parenting styles. A related body of research has considered the impact of a range of parenting practices on the development of anxiety disorders in children. The two major facets of parenting considered in these studies are lack of warmth (or parental rejection) and overcontrol. Within a cognitive framework, lack of warmth and rejecting behaviors can be seen as likely to reinforce a child's expectations that the world and others are hostile and unsupportive (Bögels and Tarrier, 2004). Overcontrol and the concomitant discouragement of independence are likely to limit the child's sense of agency and competence and to reinforce avoidance of potentially threatening situations (Parker, 1983; Chorpita and Barlow, 1998).

Evidence for associations of such parenting factors with childhood anxiety has been mixed (Wood et al., 2003; DiBartolo and Helt, 2007; McLeod et al., 2007), but with stronger and more reliable associations generally found for overcontrolling parenting. Inconsistencies in findings may partly reflect different study designs and measurement contexts and methods. Direct observation of parenting, in samples of children with diagnosed anxiety disorders rather than proxy symptoms, produces the most robust associations. A meta-analysis of studies accounting for these factors suggested that of all aspects of parenting style, a low level of autonomy granting (a feature of overcontrol) was the one most reliably associated with anxiety disorders in children (McLeod et al., 2007).

These associations can be considered in relation to quality of parent-child attachment. Attachment theory has long held that rejecting and overcontrolling parental behaviors are related to the child's level of attachment security. This general hypothesis is well supported in observations of mothers and children (Crowell and Feldman, 1991). More specifically, attachment theorists have hypothesized that limited autonomy granting and/or rejecting parental styles engender an anxious style of attachment in the child (Ainsworth and Bell, 1974; Sroufe et al., 1983). This specific hypothesis has been consistently supported in observational research (e.g., Sroufe et al., 1993).

\section{Child-driven effects and parenting factors}

While studies examining parenting styles have established that certain features are more commonly found in the context of childhood anxiety and insecure-anxious attachment (for review see Bögels and Brechman-Toussaint, 2006), researchers have attempted to establish whether such styles cause anxiety in the 
child, are the effect of having an anxious child, or result from an interaction between parent and child.

Studies pertaining to support a causal model of parenting styles that use sibling controls are problematic (Hudson and Rapee, 2002; Barrett et al., 2005) given that the controls often have considerable levels of anxiety themselves. This leaves open the possibility that parenting style is provoked by a child's anxiety. Evidence for childdriven effects was provided in a study by Moore et al. (2004) in which parenting styles such as lack of warmth and catastrophizing were found to show a main effect of child diagnosis. Further, Ghera et al. (2006) found that 4-month-old infants who responded negatively to novel stimuli and were viewed by their mothers as "difficult to soothe" received low levels of maternal sensitivity (see also Hane and Fox, 2006). The same group reported that 9-month-old infants who showed high levels of behavioral avoidance to ominous stimuli and a corresponding pattern of right frontal electroencephalogram (EEG) asymmetry (itself a correlate of continued inhibition across early childhood; see Fox et al., 2001), received low levels of maternal sensitivity (Hane et al., 2008). This result was replicated in a follow-up study of the same sample in early childhood (Hane et al., 2010).

There is therefore some evidence that child-driven effects can potentially influence the quality of the early caregiving environment by provoking a certain style of parenting response. Other than child-driven effects, however, these studies do not adequately address potential influences on maternal behavior that could be impinging on mothers' abilities to provide sensitive care. Social support and maternal anxiety are two examples of such factors and are considered in turn.

It has long been established that reported level of social support correlates with quality of caregiver behavior (e.g., Crockenberg and McCluskey, 1986), with the level of social support being of particular importance for mothers of distress-prone infants (Crockenberg and McCluskey, 1986). One study demonstrated that maternal insensitivity was predicted by the joint effect of infant distressproneness and low social support (Pauli-Pott et al., 2004) while Hirshfeld et al. (1997) demonstrated that parenting styles associated with anxiety disorders in children emerged only in anxious mothers with BI infants. Taken together, these studies suggest that infant temperament (BI) predicts later child anxiety only when accompanied by certain anxiogenic parenting styles. These styles are more readily provoked in mothers who are themselves anxious, an interaction that is more likely to occur against a background of low social support. Recent longitudinal research offers support for this complex pattern of interaction effects (Warren and Simmens, 2005; Murray et al., 2008).

Regarding parenting effects, research over the last decade has largely focused on the impact of maternal factors. In order to understand the development more comprehensively the role of fathers should also be considered (Bögels and Phares, 2008). While this is a relatively under-researched area, there is preliminary evidence for the role of paternal anxiety as a moderator of treatment outcomes for children with anxiety disorders (Rapee, 2000). Rapidly changing patterns of parenting in Westerns countries make delineation of the shared and gender specific parenting influences on emotional development an urgent social as well as psychological issue (Grossmann et al., 2005, 2006).

\section{SECTION SUMMARY}

Given their high prevalence, associated functional impairments and robust associations with the onset of other debilitating disorders, anxiety disorders warrant continued, multidisciplinary attention. While further elucidation of the genetic substrates and related biological processes by which anxiety disorders are inherited will no doubt offer exciting insights, greater understanding of the processes by which such genetic vulnerabilities may be modulated by the early environment will afford the most comprehensive etiological account.

\section{ATTACHMENT EXPERIENCES AND STRESS REGULATION}

Having reviewed literature pertinent to anxiety disorders, we now transition to integrating these findings in an attachment framework. First, we discuss normative co-regulation of stress and threat in the secure attachment relationship. We then propose a model for the dysfunction of regulation in anxious attachment and how this moderates genetic vulnerabilities and biological pathways that underpin subsequent development of anxiety disorders.

Contemporary attachment theory posits attachment as a behavioral and physiological system that is biologically based and dynamically adapting to meet the needs of the individual's particular environment (Mikulincer and Shaver, 2007). It responds to the stress provoked by environmental threats by promoting strategies that best maintain proximity to the caregiver.

Recent literature has conceptualized the stress response as an interpersonal process (Sbarra and Hazan, 2008; Luyten et al., submitted for publication), and has proposed an empirically testable and integrative framework of individual differences in stress regulation and susceptibility to anxiety disorders. Because it provides a developmental account of both normative and maladaptive stress regulation, attachment theory is best positioned to integrate findings that are proliferating in the various fields investigating stress and anxiety disorders (for a comprehensive review, see Luyten et al., submitted for publication).

\section{SECURE ATTACHMENT AND THE REGULATION OF STRESS AND ANXIETY}

Perceived threats and fear activate an individual's attachment system, prompting a series of processes that ultimately aim to regulate the stress response (Mikulincer and Shaver, 2007). These processes include primary attachment behaviors such as separation distress and subsequent proximity seeking (Sbarra and Hazan, 2008). Experimental and naturalistic studies have demonstrated this in children, adolescents, and adults (Sbarra and Hazan, 2008 for review, Mikulincer and Shaver, 2007).

If these behaviors successfully elicit the safety-promoting response of the attachment figure, the attachment system is deactivated. Over time, if the attachment figure is reliably available, attentive, and responsive, a secure attachment develops. This attachment is characterized by experiences of reassurance, a sense of safety and, ultimately, effective affect regulation. These repeated experiences become generalized as experience-expectant predictions of interactions and lead to a reduced reliance on external cues of safety (Mikulincer and Shaver, 2007). Individuals become increasingly capable of effectively regulating their stress-responses 
by calling upon mental representations of internalized attachment figures - so-called "internal working models" (Bowlby, 1973; Bretherton and Munholland, 2008). Recently, research studies have operationalized the effects of the working model as supportseeking, self-esteem, and self-worth (e.g., Lee and Hankin, 2009). Thus, securely attached individuals can efficiently regulate stress and anxiety either by seeking proximity to a reliable attachment figure in their actual environment or by mentally drawing upon past experiences in which stress was effectively co-regulated. In this way, stress regulation remains an inherently interpersonal process (Diamond and Aspinwall, 2003; Luyten et al., submitted for publication) with the attenuation of anxiety embedded in all close relationships.

Ganzel et al. (2010) have modeled the stress response in an allostasis framework that accounts for: (a) ongoing evaluations of internal resources and external demands; (b) advance physiological adjustment through anticipatory arousal; and (c) adaptation to environmental circumstances over time. This notion has been greatly enriched in contemporary attachment theory by the elaboration of the concept of mentalization (Fonagy, 1998; Fonagy et al., 2002). The role of mentalization, that is, to conceive of self and others as social agents whose thoughts, feelings, desires, and behaviors are underpinned by intentional mental states (Fonagy et al., 2002), has been highlighted as a potent factor in social cognition and particularly in stress-related interpersonal contexts (Fonagy and Luyten, 2009). There is accruing evidence that effective mentalization that enables infants to regulate negative affect, threat cues, separation anxiety, and the resulting stress states - and thus subjective as well as physiological distress - follows a pattern of intergenerational transmission (Sharp and Fonagy, 2008). A mother's mentalizing ability, that is, the parent's ability to treat the child as an psychological agent with mental states independent of their own (Fonagy and Target, 1997) predicts both secure attachment and their child's own capacity to mentalize (Meins et al., 2002; Slade et al., 2005). For instance, a distinctive marker of secure attachment is the capacity to tolerate negative affect (Sroufe, 1996). Crucial to these processes is the caregiver's capacity to attenuate the child's stress or anxiety once its attachment system has been activated. A child's general sense of a secure base not only enables them to explore their environment freely but, more importantly, enhances their ability to contemplate own mental states and those of others. Studies have demonstrated attachment security to be a predictor of performance on diverse theory of mind (ToM) tasks, including false belief tasks in preschoolers (e.g., Arranz et al., 2002), and of the development of socio-cognitive capacities which support ToM, such as internal state language (i.e., emotion regulation and self-awareness vocabulary) in toddlers (e.g., Lemche et al., 2007). In critical contexts, these mentalizing capacities are online only once the attachment system has been downregulated after a threat or stressor has abated (Luyten et al., submitted for publication). This in turn, creates positive feedback loops for the possibility of the adjustment and regulation of impending stress response. In an attachment-based approach secure attachment is therefore viewed as the interpersonal training ground for the infant in which social cognition or mentalizing and their concomitant neural correlates are developed. These capacities allow for allostatic accommodation by enabling individuals to recognize and to regulate stress-related states (Schulkin, 2010).

As noted earlier, there is increasing evidence that attachment security serves a protective function by promoting resilience to the impact of stress mainly via anxiolytic and trust-enhancing effects mediated by the neuropeptide oxytocin (Heinrichs et al., 2003; Powers et al., 2006; Feldman et al., 2007; Heinrichs and Domes, 2008). Moreover, studies investigating stress responsivity in both human and animals have demonstrated that a secure attachment leads to an "adaptive hypoactivity" of the HPA-axis (Gunnar and Quevedo, 2007). Conversely, in a study of human adults low-quality parenting was found to be linked with elevated salivary cortisol levels during experimentally induced psychosocial stress (Gunnar et al., 2007). Such parenting was also linked to an increased release of dopamine in ventral striatal areas, which is a factor in the response to aversive stressful stimuli (Pruessner et al., 2004).

A further feature of a secure attachment is its encouragement of effective seeking of supportive attachment relationships throughout the lifespan. This is in line with contemporary attachment theory which posits that a attachment security leads to a cyclical process of "broaden and build" (Fredrickson, 2001) in which the individual experiences a sense of personal agency, can effectively regulate emotions and conflicts and engage in exploratory behaviors (Mikulincer and Shaver, 2007). Such behaviors direct the individual into new environments (broaden) that require adapting to new challenges (build). Moreover, broadening experiences have been shown to result in the recruitment of supportive relationships (Hauser et al., 2006) which further enhances resilience in the face of stress (Masten and Obradovic, 2008). Additional evidence for this notion is provided by functional neuroimaging studies that demonstrate an inverse relationship between participants' cortisol levels during social stress and the extent of their supportive social network (Eisenberger et al., 2007), with individual differences in activity of brain areas associated with social separation (Brodmann area 8 , dorsal anterior cingulate cortex) found to mediate this relationship indicating a "protective" effect of social support on the neural processing of social threat and subsequent HPA reactivity. Furthermore, secure attachment has been associated with stronger decreases in state anxiety levels following laboratory-induced stress exposure (Ditzen et al., 2008). More interestingly, an interaction effect between combined social support and secure attachment resulted in even lower post-stress anxiety levels. Secure attachment and a normative stress response, in the current model, are closely linked with adaptive allostasis and neural plasticity (Ganzel et al., 2010; McEwen and Gianaros, 2010), a process conceived of as a buffer against future environmental challenge and conferring resilience to the development of psychopathology (Gluckman et al., 2007). The capacity to retain high levels of mentalization when faced with threat or anxiety is supposed to play a key mediating role therein, mainly by keeping regulatory brain regions such as the prefrontal cortex engaged during experiences of stress and attachment activation and by enabling a fast recovery from the momentary loss of this capacity. This, is turn, results in a reinforced feeling of attachment security, a sense 
of agency and autonomy during successful affect regulation, facilitated by undistorted perception and representation of self and others (Fonagy and Luyten, 2009).

There is increasing evidence that the interplay between attachment activation, stress-related arousal, and continuing mentalizing is subserved by both the activation of mesocorticolimbic dopaminergic reward circuits and stress attenuating (Neumann, 2008; Fonagy and Luyten, 2009) and anxiolytic effects of oxytocin (Heinrichs et al., 2003; Kirsch et al., 2005; Ditzen et al., 2009; Kubzansky et al., 2009; Quirin et al., 2010). Given that oxytocin has been implicated in the parent-infant attachment relationship (e.g., Gordon et al., 2008; Strathearn et al., 2008), the attachment system may play a key role in the functioning of neural systems involved in anxiety processing. Oxytocin thus provides a link to the attachment system and has been shown to enhance experiences of secure attachment in an experimental setting (Buchheim et al., 2009). Because of the impairments in attachment in insecurely attached individuals, the quality of early experiences seems to have differential effects on the oxytonergic system (Heim et al., 2009; Bartz et al., 2010) and peripheral oxytocin levels in mothers watching cues of their infants (Strathearn et al., 2009).

\section{INSECURE ATTACHMENT, DYSFUNCTIONAL STRESS REGULATION, AND THE DEVELOPMENT OF ANXIETY DISORDERS}

Given that the primary evolutionary function of the attachment system is to maintain an infant's proximity to the caregiver, the system has to allow for adaptation to sub-optimal caregiving, as in cases where the caregiver is inconsistently responsive, unavailable, or abusing. Therefore, when faced with stress or threat and the primary attachment strategies have failed to elicit appropriate caregiving behaviors, the infant utilizes so-called secondary strategies in order to promote proximity and regulate anxiety. These secondary strategies are characterized by "hyperactivating" or "deactivating"1 modes of stress and anxiety regulation (Cassidy and Kobak, 1988; Mikulincer and Shaver, 2007; Roisman, 2007). Hyperactivating strategies are central to an attachment account of anxiety disorders given their initiation in response to anxiety states, and are typically observed in anxiously attached individuals. Such strategies are characterized in infancy by frantic attempts to gain the attention of the attachment figure and develop when the infant's previous interactions have required up-regulation of seeking behaviors in response to an inattentive, preoccupied, or anxious caregiver (Mikulincer and Shaver, 2008). If repeated over time, these experiences serve to consolidate expectations of unreliable and unpredictable responses from the attachment figure and therefore create anticipatory anxiety and heightened vigilance for threat rather than successfully regulating anxiety states. The frantic demanding of support and constant activation of the attachment

\footnotetext{
${ }^{1}$ Deactivating (minimizing) strategies are typically observed in individuals with a avoidant style of attachment, and are characterized by attempts to downregulate and suppress the attachment system in times of stress. Behaviorally, deactivating strategies are observable in self-soothing activities, assertions of independence, and the denial of attachment needs (Cassidy and Kobak, 1988). Deactivating strategies are derived from a history of attachment experiences in which the caregiver was rejecting, emotionally distant, or prone to withdrawal when called upon. A reliance upon deactivating strategies strengthens expectations of attachment figures as unavailable, characteristic of a dismissive attachment in adulthood.
}

system may only allow for temporarily effective stress regulation but in the long run "undermine the goal of recruiting a soothing figure" (Luyten et al., submitted for publication) and compromise the establishment of social networks to provide supportive care (Campbell et al., 2005). At the intrapersonal level, these dynamics are characterized by autonomy-dependency conflicts which in turn affect interpersonal functioning Joraschky and Petrowski (2008). Furthermore, Mikulincer and Shaver (2007) demonstrated that secondary strategies impact on the primary attachment strategy of fear and threat appraisal via inhibitory or excitatory feedback loops (with the latter being of particular relevance regarding hypervigilance and HPA-axis functioning in anxiety disorders). Anxiety therefore increases the seeking of proximity, while separation from the attachment figure in turn increases anxiety and withdrawal (Luyten et al., submitted for publication).

While evolutionarily advantageous in early childhood, these strategies are associated with maladaptive outcomes in later life due to their detrimental impact on interpersonal functioning (Mikulincer et al., 2010). The resulting anxious pattern of attachment is then likely to persist into adulthood (anxious-ambivalent attachment) and represents the predominant mode of stress regulation. In individuals who have experienced highly unpredictable and abusive caregiving environments, attempts to regulate anxiety states are observed to be characterized by a chaotic oscillation between both hyperactivating and deactivating strategies - socalled disorganized attachment (Main and Solomon, 1986; Main and Hesse, 1990). Both anxious and disorganized attachment patterns have been associated with the development of anxiety disorders (Manassis et al., 1994; Warren et al., 1997).

\section{ATTACHMENT RESEARCH IN RELATION TO ANXIETY DISORDERS}

Whilst not considered inherently pathological, insecure infant attachment patterns, and the reliance upon secondary strategies increases the likelihood of psychopathology. Specifically, anxious attachment has been consistently associated with internalizing problems (e.g., Colonnesi et al., 2011) and a growing body of research lends support to the view that anxious attachment, and therefore the use of hyperactivating strategies, predisposes an individual to various anxiety disorders (Colonnesi et al., 2011 for meta-analysis). For example, it has been shown that a history of anxious attachment measured at 12 months of age puts children at risk of developing anxiety disorders in childhood and adolescence even when maternal anxiety and temperament are controlled for (Warren et al., 1997). Bosquet and Egeland (2006) found attachment history was moderately correlated with self-reports of anxiety at the age of 16 . Further, childhood anxiety classification was predictive of negative adolescent peer relationships which in turn predicted anxiety symptoms. In another longitudinal study, Bar-Haim et al. (2007) linked anxious-ambivalent attachment at the age of 12 months with higher levels of school phobia 10 years later. This association was, however, only found in boys.

Hyperactivating strategies therefore hold a relatively unique position of predicting an array of transdiagnostic anxiety behaviors. Anxiously attached children experience constant worry about being abandoned and left alone when fear is experienced (Sroufe, 1996). This response is characterized by chronic hypervigilance toward the social environment which may give rise to 
the development of anxiety symptoms (Cassidy and Berlin, 1994; Weinfield et al., 1999).

In adulthood, the manifestation of anxiety disorders is linked with ambivalent (anxious) attachment classification (Fonagy et al., 1996; Rosenstein and Horowitz, 1996; Dick et al., 2005; Colonnesi et al., 2011) and negative attachment-related experiences such as overprotective parenting or abandonment and separation distress (DeRuiter and van Ijzendoorn, 1992; Cassidy, 1995; Bandelow et al., 2002). In some of these studies (Manassis et al., 1994; Fonagy et al., 1996) and particular when investigating PTSD (Kobak et al., 2004; Stovall-McClough and Cloitre, 2006 for review), there seems to be a high prevalence of disorganized attachment suggesting that childhood trauma or loss can give rise to particular anxiety disorders.

More importantly, the study by Manassis et al. (1994) demonstrates, albeit with a small sample, that $80 \%$ of the children of mothers diagnosed with anxiety disorders were classified as insecurely attached with $65 \%$ of them matching their mother's attachment classification.

In line with our framework it has to be noted that anxious attachment itself is, at least in part, influenced by genetic contributions. This seems to be more relevant when the style of attachment is assessed via self-reports. Brussoni et al. (2000) found that $25 \%$ of the variability in adult attachment measured with the Relationship Scales Questionnaire was accounted for by genes. Using a twin study design, Crawford et al. (2007) demonstrated that $40 \%$ of the variance was attributable to heritable factors, a finding recently confirmed by Picardi et al. (2010) who reported $45 \%$ heritability. Behavioral genetics studies focusing on attachment classifications obtained with interview-based instruments, in contrast, highlight the role of shared environmental factors with only little influence accounted for by genes in the contribution to the transgenerational transmission of attachment in children (Bokhorst et al., 2003; Fearon et al., 2006; Bakermans-Kranenburg and Ijzendoorn, 2007). These inconsistencies might result from different methodological approaches and the differential effect of gene $\mathrm{x}$ environmental interplay depending on the timing of when genetic effects come into play.

\section{CONSEQUENCES OF HYPERACTIVATING STRATEGIES}

As indicated earlier, secondary attachment strategies might be temporarily adaptive in a specific context or even at a societal level (Simpson and Belsky, 2008; Ein-Dor et al., 2010), but in the long run fail to attenuate stress effectively and result in increased allostatic load. More specifically, the heightened subjective and physiological stress reactivity found to be associated with hyperactivation has been shown to affect core processes involved in allostatic adaptation on a behavioral, endocrinological, and neural level.

\section{Compromised broaden and build features}

The attachment-based coping strategies associated with hyperactivation prohibit the ability of the individual to "broaden and build." Potentially supportive and competent others, especially in close relationships, are experienced as untrustworthy and/or unpredictable in their support and these expectations are combined with chronic worry about abandonment (Campbell et al.,
2005; Miculincer and Shaver, 2009). Psychodynamic accounts furthermore highlight the role of conflictuous interpersonal functioning (e.g., Joraschky and Petrowski, 2008). Further, the use of such strategies inhibits motivational systems responsible for exploratory, affiliative, and caregiving behaviors (Mikulincer and Shaver, 2005). Other factors characterizing hyperactivating behavior, such as a negative view of self, a lack of self-efficacy, and the tendency to avoid fears - all inversely correlated with findings regarding resilience (Cicchetti, 2010) - reinforce the systems responsible for hyperreactivity to stress.

\section{Dysfunctional HPA-axis}

The excessive use of behavioral hyperactivation has been linked to physiological and neuroendocrinological hyperresponsivity (Lupien et al., 2009). In a large prospective cohort study, for instance, insecure-anxious (resistant) children displayed elevated cortisol levels after being exposed to a separation paradigm (Luijk et al., 2010). Similarly, in adults, hyperactivation has been found to result in an altered and more sensitive HPA-axis (Powers et al., 2006; Diamond et al., 2008; Gordon et al., 2008) and to have direct effects on reducing hippocampal cell density (Quirin et al., 2011) which might reflect a stress-driven neurotoxic impact on the glucocorticoid system. These indicators of allostatic load together with the previously reviewed effects of stress and anxiety on HPA-axis functioning suggest that chronic wear and tear entails that the once regulatory and anticipatory functions of the HPA-axis are rendered to conferring vulnerability to psychopathology (Schulkin, 2010). Most notably, the acquisition of prior allostatic load as observed in attachment experiences characterized by anxiety and ineffective stress regulation might impair the individual's capacity to accommodate to a current or future stressor (Ganzel et al., 2010).

\section{Effects of allostatic load on the neural circuits - mentalization deficits under heightened stress and in the face of anxiety - biobehavioral switch}

The core emotional regions of the brain (the fronto-limbic circuit), as outlined above, are the primary and central mediator of allostatic load as they are involved in the immediate stress response but also iteratively update evaluations of stress and threat-related environmental challenge (Ganzel et al., 2010). Together they coordinate physiological and behavioral responses to stress and require the effective recruitment of additional neural resources due to increased attentional and processing load. (Vuilleumier et al., 2001; Davidson et al., 2004). As these neural circuits represent the main interface between changes in the environment and the individual's accommodation to it they have been shown to be vulnerable to accrual of stress load and resulting wear and tear (LeDoux, 1996; Phelps, 2006; McEwen, 2007; Fonagy and Luyten, 2009; Rodrigues et al., 2009; Ganzel et al., 2010) and are most malleable during fetal and early childhood periods (National Scientific Council on the Developing Child, 2005). Arnsten (2009) has drawn attention to the stress signaling pathways and the neuromodulatory alterations that markedly impair PFC functioning, the ventromedial section in particular. More specifically, the impact of allostatic load can damage brain circuits due to an overproduction of neurochemicals involved in the stress response (Bremner et al., 1995; 
Gould et al., 1997; Ganzel et al., 2010). These effects of significantly stressful events on neural processing have been studied in great detail in fear consolidation and fear extinction paradigms which are associated with anxiety and affected by hyperactivation strategies (Wellman, 2001; Izquierdo et al., 2006; Milad et al., 2009; Rodrigues et al., 2009).

More importantly, following the biobehavioral model put forward by Luyten et al. (submitted for publication), sustained hyperactivation in the face of anxiety or stress is directly linked to a relative switch in activation from cortical to subcortical brain systems, from slow, reflective regulation to a rapid, reflexive response (see also Mayes, 2006; Fonagy and Luyten, 2009; Johnson et al., 2011). This arousal-dependent switch furthermore affects the capacity to mentalize and modulates the neural network underpinning this faculty. More broadly, on a neural level, what can be observed is a "switch from non-stress to stress conditions" (Arnsten, 2009). Brain areas that have been consistently shown to underpin mentalization include the medial PFC, superior temporal sulcus, and temporal lobes (Gallagher and Frith, 2003; Frith and Frith, 2006; Lieberman, 2007). In keeping with this notion, Fraley et al. (2006) showed that anxious attachment is associated with hypervigilance in perception of emotional expression and poorer affect judgments.

Beyond the well-established effects on neural circuitry underpinning anxiety, there is strong evidence from electrophysiology studies and functional neuroimaging that anxiously attached individuals employing hyperactivating strategies under-recruit prefrontal brain regions involved in emotion regulation, display a neurobiologically supported bias toward memories of negative valence and respond with amygdala hyperactivation to negative social feedback (Gillath et al., 2005; Zilber et al., 2007; Vrticka et al., 2008; Zhang et al., 2008). Moreover, it has been shown that when comparing the effect of a general stress induction versus an attachment-related (interpersonal) stress induction, only the latter results in a relative deactivation of core areas associated with mentalization. In this study of a normal population, when inferring mental states of others during the Reading the Mind in the Eyes Test (Baron-Cohen et al., 2001), Nolte et al. (under review) found that it was only after exposure to attachment stress that activation decreased in the inferior frontal gyrus (a part of the prefrontal cortex), the posterior temporal sulcus, and the temporoparietal junction combined with stress-driven alterations of functional connectivity. It can be hypothesized that these stress-related alterations will be more pronounced in anxious individuals, although this has yet to be investigated.

Together, these findings provide preliminary evidence that the mitigating role of mentalizing is reduced in anxious individuals due to excessive use of hyperactivating strategies. Consistent with this theory, Milrod and colleagues (Rudden et al., 2008) report preliminary evidence that individuals with Panic Disorder display no general deficits in mentalizing but markedly impaired mentalization related to threat and anxiety cues.

\section{SECTION SUMMARY}

The hallmarks of hyperactivation strategies in response to stress and anxiety states are a low threshold for activation of the attachment system, a low threshold for relative deactivation of brain areas involved in controlled, reflective social cognition, and mentalization as well as amygdala hyperreactivity resulting in neuroendocrinological hyperresponsivity. The current model locates the main "programming" of these circuits and the neural acquisition of allostatic adaptation (i.e., plasticity) in the early attachment experiences. The ineffective down-regulation of stress which is linked with impaired interpersonal functioning and long-term consequences of allostatic load can lead to an exhaustion and dysfunction of the stress response system with increased risk for stress-related psychopathologies such as anxiety disorders.

\section{AN ATTACHMENT-BASED DEVELOPMENTAL FRAMEWORK OF ANXIETY DISORDERS}

We conceptualize the attachment system as a central organizer of biological, genetic, and environmental influences on the development of dysfunctional stress-regulatory processes and fear responses that underpin anxiety disorders. The model, based on the preceding review is presented in Figure 1. Component sections are discussed in turn.

\section{CHILD FACTORS}

Genetic influences have been demonstrated to account for temperamental factors (BI) which may, in some instances, represent child-driven effects in the evocation of certain parenting styles. Individual differences in attachment have also been demonstrated to be influenced by genetic factors, although to a lesser degree. The direct contribution to anxiety disorders accounted for by genes is most likely the result of multiple loci additive and/or interactive gene effects (Norrholm and Ressler, 2009; Figure 1, Box 1).

However, as we have seen, stress sensitivity, and temperament at birth, is modifiable by the effects of prenatal environment given that, maternal stress and anxiety during pregnancy can lead to a sensitization of the HPA-axis. Thus, characteristics the infant is born with could represent an in utero adaptation to the stress regulation style of the mother.

\section{PARENTAL FACTORS}

Multiple parental factors have been outlined as possible contributors to the development of dysfunctional stress regulation of the child. Such factors have been delineated as the presence of an anxiety disorder (or preclinical anxiety, both entailing HPA-axis alterations), low social support, parental insecure attachment, and low mentalization capacity (Figure 1, Box 2).

\section{THE ATTACHMENT RELATIONSHIP AS A DIALECTICAL SYSTEM ORGANIZING EARLY EXPERIENCES}

Together, or individually, parental factors interact with child factors outlined above, within the context of the early attachment relationship. The proposed mechanisms by which these factors can affect the parent's capacity to effectively co-regulate the child's stress include the modeling of anxiety responses, the reinforcement of threat cues in the environment (and their avoidance) and parenting styles characterized by overcontrol of the child and limited autonomy granting as observed in caregiver responses to anxiously attached children (Figure 1, Box 3). 


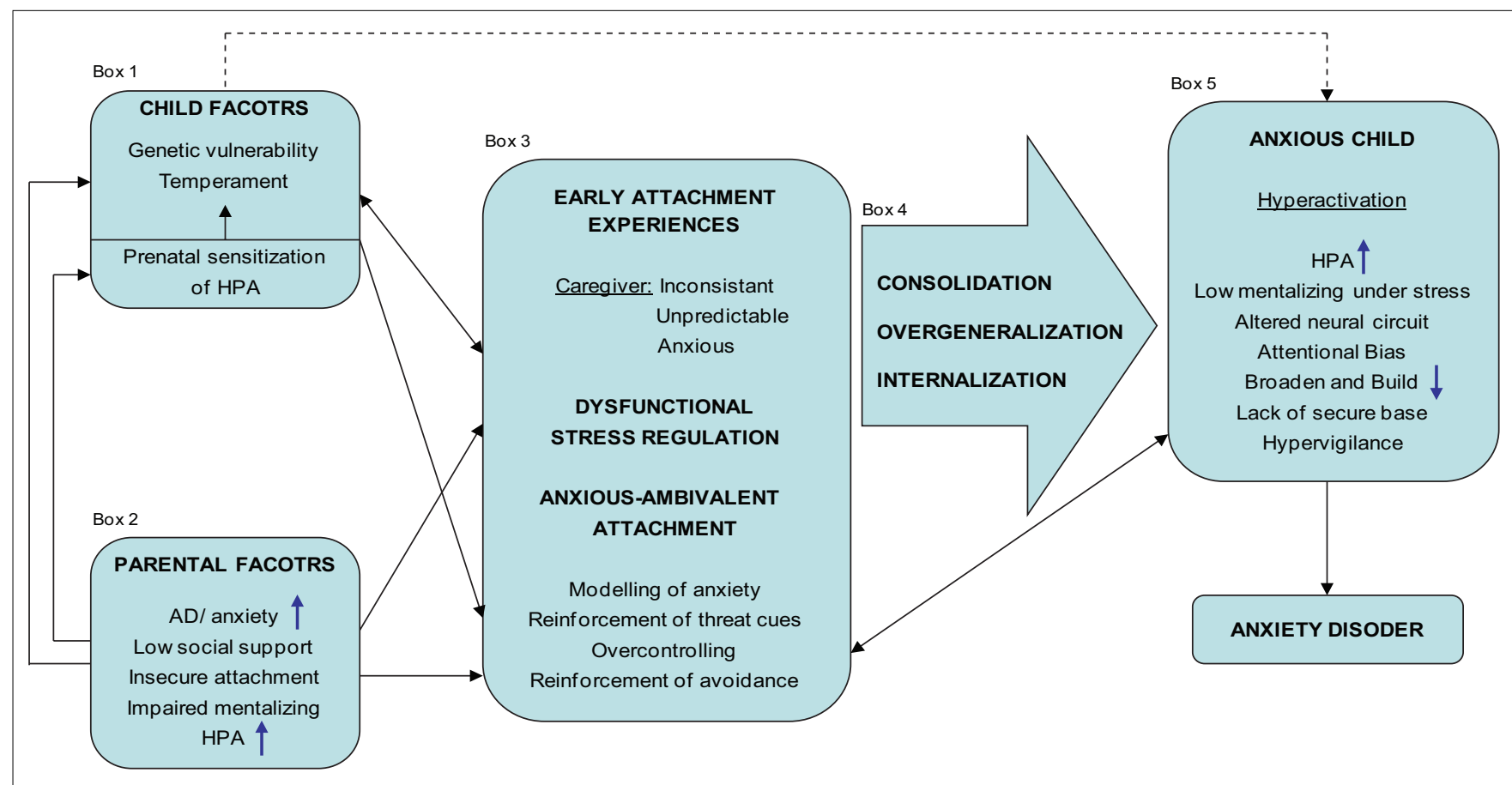

FIGURE 1 | A developmental model of the attachment-moderated interaction of risk factors in the development of anxiety disorders. Black bolts from one box to another indicate either uni- or bidirectional effects and refer to the box as a whole. Blue bolts inside boxes indicate either an increase or decrease of the magnitude of the respective feature.

\section{FROM EARLY ATTACHMENT EXPERIENCE TO A RISK PROFILE}

It is proposed that the development of a stress regulation style characterized by hyperactivating strategies is adaptive to the child's particular early environment. However, this pattern of responsivity, once internalized, leads to an overgeneralized application of these strategies in the face of stress, a process that over time becomes consolidated. Consolidation occurs as the individual detects more threat in the environment in the first instance, avoids these perceived threats, and subsequently limits the repertoire of experience that could potentially correct and adjust the internalized expectations of the environment as ultimately unpredictable and threatening (attentional bias to threat). These maintaining factors echo those delineated in both cognitive and learning-theory accounts of the persistence of fear responses in anxiety disorders (Wells, 1997; LaBar and Cabeza, 2006; Mineka and Zinbarg, 2006; Britton et al., 2011; Figure 1, Box 4).

These processes are hypothesized, in the current model, to represent pathways from insecure attachment experiences to the presentation of chronic anxiety-related phenomena which, in turn, predispose the child to the development of full anxiety disorder symptomatology depending on vulnerability factors and life events.

\section{THE "ANXIOUS CHILD": A PROFILE OF RISK}

Following the development of hyperactivating strategies and their persistent utilization over time, the anxiously attached child is characterized by a discernable repertoire of stress-responses. Such phenomena include (1) the lack of a secure base and concomitant poor exploratory behaviors, perception of reduced control, an attentional bias to threat, (2) chronic reliance upon hyperactivating strategies and hypervigilance of the social environment with neurophysiological correlates of a sensitized HPAaxis and altered fronto-limbic neural circuitry, and (3) compromised social-cognitive capacities under stress with slow recovery of mentalization (Figure 1, Box 5).

The various aspects of this combined profile of stress responsivity have been shown within this review to associate with the development of anxiety disorders. The mechanisms by which these response characteristics ultimately lead to the expression of a clinical anxiety disorder likely include the chronic sensitization of the HPA-axis and neural systems, or the impact of subsequent stressful life events that trigger a style of responding that, while adaptive in early childhood, proves maladaptive in adult environments.

Furthermore, the various factors that may influence the expression of anxiety disorders likely interact. The interplay between these different risks at different developmental stages, congruent with the developmental principle of multifinality (Cicchetti and Rogosch, 1996; Luyten et al., 2008), may give rise to different clinical presentations of anxiety disorders. Further longitudinal research is needed in this area to investigate these assumptions.

\section{LINKS IN THE CHAIN: THE ROLE OF EPIGENETIC FACTORS IN THE DEVELOPMENT OF STRESS REGULATION}

As demonstrated throughout this review, the understanding of interactions between genetic and environmental factors are key to elucidating how early experiences confer risks for anxiety disorders that persist throughout the lifespan (Rutter et al., 2006). Epigenetic processes, through which events in the environment 
alter the activity and expression of genes without altering DNAsequence, are key candidates in explaining how the effects of early attachment experiences manifest beyond the early years (for review see Murgatroyd and Spengler, 2011).

While attention to these epigenetic processes is developing rapidly, many key hypotheses rely on findings in animal research in which early environments can be experimentally controlled. Data from rodent models indicate that the long-term effects of maternal caregiving appear to depend upon alterations in differentiation of those neurons involved in down-regulation of the stress-response (Meaney et al., 1996; Meaney, 2010), a process involving glucocorticoid feedback systems and related levels of corticotropin releasing hormones (CRH; Plotsky and Meaney, 1993). Further, the offspring of mothers providing high quality, attentive care exhibit reduced levels of $\mathrm{CRH}$ in the hippocampus and a reduced sensitivity of the HPA-axis when compared with rat pups of mothers who had not provided such sensitive caregiving (Francis et al., 1999). These environmentaldependent effects are hypothesized to be underpinned by epigenetic alterations in DNA methylation processes (Weaver et al., 2004) and are in line with our model which holds the early interactions within the attachment context as the vital component in the development of stress-regulatory capacities that persist into adulthood.

More recent studies that examine these processes in humans have shown that post-mortem hippocampal tissue from individuals who have completed suicide following a history of depression and early adversity, is marked by altered GR promoter methylation (McGowan et al., 2009). In comparing GR promoter methylation in these subjects with those who had committed suicide (with or without a diagnosis of depression) but with no known history of early adversity, Alt et al. (2010) demonstrated that altered GR promoter methylation was characteristic of subjects with early adversity only, thus addressing the question of whether such markers may be correlates of mood disorders irrelevant of early experiences. Such findings represent initial evidence that epigenetic programming in animal models may extrapolate to human studies of psychopathology associated with sub-optimal early caregiving environments. How such epigenetic alterations could contribute causally to the emergence of anxiety disorders is yet to the be understood, and the search for so-called "epigenetic biomarkers" of psychiatric presentations (Murgatroyd and Spengler, 2011) is made complicated by the limited evidence available indicating that psychopathology can be present without the presence of epigenetic markers (Alt et al., 2010).

Epigenetic processes are hypothesized to underpin the developmental plasticity of an organism, characterized by biological adaptations made early in life that remain in order to enhanced biological preparedness for later, similar environments. While the evolutionary function of such plasticity is clear, adaptations made through epigenetic processes may ultimately increase vulnerability for anxiety-related diseases as the strategies they have promoted may prove redundant and pathognomonic in later environments. Thus, the process of overgeneralization and consolidation in the current model could be taken as representative of the inflexible application of strategies initially promoted via epigenetic mechanisms due to their adaptive properties.

\section{CONCLUSION}

The model presented conceptualizes anxiety disorders as caused and maintained by a complex interplay between genetic, environmental, and epigenetic contributions - a multifactorial etiology which ultimately results in dysfunctional stress regulation and fear appraisal strategies that are acquired within the early attachment relationship. These strategies, in our model, are maintained by alterations of social-cognitive as well as biological functions. Emotional strategies adopted by a child may be associated with cumulative allostatic load and subsequent "wear and tear" effects. These converge on the neural pathways involved in processing of signals and experiences associated with anxiety and stress. We suggest that chronic anxiety conditions entail the triggering of a biobehavioral switch causing a shift from more controlled, reflective mentalization to more automatic, reflexive modes (McEwen, 2007; Luyten et al., submitted for publication). This in turn increases the individual's vulnerability to further potentially stressful experiences leading to a hyperactivation of strategies that generate salience for somatosensory and perceptual experiences associated with the activation of the attachment system and the potential of an experience of loss.

An attachment-based framework integrates isolated strands of research that successfully characterized processes inherent to anxiety disorders. A further advantage of this framework is its potential to explain individual differences in stress and fear-triggered regulatory capacities. Distinct characteristic patterns of stress responsivity are associated with the different attachment styles, which may go some way toward explaining differences between anxiety-related conditions. In common to the development of anxiety problems, however, is an overgeneralization of predominantly hyperactivating stress-regulatory strategies developed in an individual's specific attachment relationship.

\section{DISCUSSION/IMPLICATIONS}

While delineation of disorder-specific etiological pathways has been beyond the scope of the current paper, the framework presented can account for the heterogeneity of presentations of anxiety-related psychopathology, given its focus on the interplay of genetic and environmental factors that potentially contribute to the development of the various anxiety disorders.

The model therefore generates empirically testable hypotheses regarding specific developmental pathways and factors moderating the risk for or resilience to anxiety disorders.

Longitudinal neuroscientific developmental research will be required in order to elucidate the complex interactions that are likely to result in phenomenologically different types of anxiety disorders, and to further understand the role of anxiety and attachment in the emergence of other major psychopathologies, most notably depressive disorders. Research to date has been primarily cross-sectional and the serial sequence of brain changes that characterize the emergence of anxiety problems is not known. Much of the interactional processes discussed in this review are assumed rather than observed to be occurring in chronological time. The limitation this imposes on theorization principally entails limited understanding of the phenomenon of resilience, the processes whereby risks fail to be translated into clinically 
significant problems. While we understand more about brain changes that create pathogenic outcomes, far less is known about adaptations that protect the mind of the child, despite adversity (Hauser et al., 2006). Further, future research should devote more attention to individual differences in clinical outcomes. For instance, the extent to which deactivating strategies are used may influence the clinical expression of anxiety problems, may be dependent on contextual factors or could even protect against the development of anxiety-related symptomatology. For example, within the maltreatment literature, findings from studies of HPA-axis responsivity in children and adolescents with histories of early adversity have been mixed (Tarullo and Gunnar, 2006) with hyperresponsivity not consistently found (De Bellis et al., 1994). A study by Kaufman et al. (1997) showed that hyperresponsivity may be dependent upon the child's ongoing exposure to a stressful environment. Thus, further maltreatment research might fruitfully examine the insecure attachment relationship as an example of chronic exposure to a stressful environment, potentially differentiated in its pathognomonic effects from more isolated episodes of maltreatment or adversity. The attachment framework might thus shed light on some currently contradictory findings within the maltreatment literature, as well as providing a conceptual framework for understanding mechanisms by which such sub-optimal caregiving can give rise to such differential outcomes. For example. disorganized attachment, where the caregiver's affect regulation is highly inconsistent (Fonagy and Luyten, 2009), may be associated with more severe developmental outcomes related to anxiety and have been shown to impact substantially on neurobiological development (see McCrory et al., 2010 for a review) with evidence for gender-specific stress responsivity (Kirschbaum et al., 1995; Kudielka and Kirschbaum, 2005). The disorganization of attachment possibly entails the loss of the interpersonal underpinning that is at the root of epistemic trust undermining the individuals confidence in exploring their environment and reducing suspicion through testing and exposure of cultural knowledge as well as a physical world (Fonagy, 1998). Modern attachment theory argues that human infants have genetically inbuilt "healthy" social expectations (Baillargeon et al., 2010). Social experience is developmentally "good enough" when it complies with these expectations; in other words it fits in with biologically prepared mechanisms which evolved to transmit human culture and is consistent with neural development (i.e., the capacity to integrate new information; Fonagy et al., 2007). Meeting these basic expectations

\section{REFERENCES}

Ainsworth, M. D. S., and Bell, S. M. (1974). "Mother-infant interaction and the development of competence," in The Growth of Competence, eds K. Connolly and J. Bruner (New York: Academic Press), 97-118.

Albers, E. M., Riksen-Walraven, J. M., Sweep, F. C. G. J., and de Weerth, C. (2008). Maternal behavior predicts cortisol recovery from a mild everyday stressor. J. Child Psychol. Psychiatry 49, 97-103.

Alt, S. R., Turner, J. D., Klok, M. D., Meijer, O. C., Lakke, E. A.,

is inherent to secure attachment and their violation can be toxic because not only does this "teach" the infant inappropriate content but it undermines the biological and psychological mechanisms for the social acquisition of knowledge and the emergence of an effectively biologically functioning agentive sense of self.

Finally, the model may have important implications for clinical interventions. There is already accumulating evidence for the efficacy of interventions informed by attachment theory in a variety of clinical presentations (Brisch et al., 2003; Bakermans-Kranenburg et al., 2008; Dozier et al., 2009; Fonagy and Luyten, 2009; Suchman et al., 2010). Secure attachment is isomorphic with inducing in the infant/child a sense of epistemic trust which may be seen as indicating to the infant/child that the information relayed by the adult charged with conveying key cultural meanings (Tomasello et al., 2005) may be trusted. This has important implications for therapy for children - as the mind is found within the other and not within itself we may say that evolution has "prepared" children's brains for psychological therapy. They are eager to learn about the opaque mental world from those around them and they are prepared to learn most readily about minds in conditions of epistemic trust. Thus, a therapist ignores the persons to whom the child naturally turns for knowledge at their peril. Preliminary support for superior outcomes when treating the parent or family of children with anxiety disorders (compared to treatment focusing on the child only) exists, mainly for cognitive behavioral approaches (Ginsburg and Schlossberg, 2002; Creswell and Cartwright-Hatton, 2007; Creswell et al., 2008; Kendall et al., 2008). Therapy is not just about the what but the how of learning. It is about opening the child's mind so (s)he once again can trust the social world by changing expectations This review and proposed model emphasizes the importance of considering an attachment-based framework in interventions for the treatment of childhood anxiety disorders in particular in identifying the attachment relationship as a key target of clinical work, alone, or in addition to pharmacological or other treatment components. Further research therefore should address process and outcome factors in relation to increasing attachment security and enhancing mentalizing capacities in combination with the underlying neurobiological substrates.

\section{ACKNOWLEDGMENTS}

The authors would like to thank Alexander Blasdel and Jennifer McGowan for comments on an earlier draft of the manuscript.

response monitoring in comorbidity. J. Child Psychol. Psychiatry 40, 57-87.

Arnsten, A.F. (2009). Stress signalling pathways that impair prefrontal cortex structure and function. Nat. Rev. Neurosci. 10, 410-422.

Arranz, E., Artamendi, J., Olabarrieta, F., and Martín, J. (2002). Family context and theory of mind development. Early Child Dev. Care 172, 9-22.

Baillargeon, R., Scott, R. M., and He, Z. (2010). False-belief understanding in infants. Trends Cogn. Sci. (Regul. Ed.) 14, 110-118.
Bakermans-Kranenburg, M. J., and Ijzendoorn, M. H. (2007). Research Review: genetic vulnerability or differential susceptibility in child development: the case of attachment. J. Child Psychol. Psychiatry 48, 1160-1173.

Bakermans-Kranenburg, M. J., Van Ijzendoorn, M. H., Mesman, J., Alink, L. R. A., and Juffer, F. (2008). Effects of an attachmentbased intervention on daily cortisol moderated by dopamine receptor D4: a randomized control trial on 1- to 3-year-olds screened for 
externalizing behavior. Dev. Psychopathol. 20, 805-820.

Bandelow, B., Spath, C., Tichaner, G. A., Brooks, A., Hajak, G., and Ruther, E. (2002). Early traumatic life events, parental attitudes, family history, and birth risk factors in patients with panic disorder. Compr. Psychiatry 43, 269-278.

Bar-Haim, Y., Lamy, D., Pergamin, L., Bakermans-Kranenburg, M. J., and van Ijzendoorn, M. H. (2007). Threat-related attentional bias in anxious and nonanxious individuals: a meta-analytic study. Psychol. Bull. 133, 1-24.

Baron-Cohen, S., Wheelwright, S., Hill, J., Raste, Y., and Plumb, I. (2001). The "Reading the Mind in the Eyes" Test, revised version: a study with normal adults, and adults with Asperger syndrome or highfunctioning autism. J. Child Psychol. Psychiatry 42, 241-251.

Barrett, P., Rapee, R., Dadds, M., and Ryan, S. (1996). Family enhancement of cognitive style in anxious and aggressive children. J. Abnorm. Child Psychol. 24, 187-203.

Barrett, P. M., Fox, T., and Farrell, L. (2005). Parent-child interactions with anxious children and their siblings: an observational study. Behav. Change 22, 220-235.

Bartz, J. A., Zaki, J., Ochsner, K. N., Bolger, N., Kolevzon, A., and Ludwig, N. (2010). Effects of oxytocin on recollections of maternal care and closeness. Proc. Natl. Acad. Sci. U.S.A. 107, 21371-21375.

Beck, A. T. (1976). Cognitive Therapy and the Emotional Disorders. New York: International Universities Press.

Beck, A. T. (2008). The evolution of the cognitive model of depression and its neurobiological correlates. Am. J. Psychiatry 165, 969-977.

Beck, A. T., and Emery, G. (1985). Anxiety Disorders and Phobias: A Cognitive Perspective. New York: Basic Books.

Beesdo, K., Bittner, A., Pine, D. S., Stein, M. B., Hofler, M., Lieb, R., and Wittchen, H. U. (2007). Incidence of social anxiety disorder and the consistent risk for secondary depression in the first three decades of life. Arch. Gen. Psychiatry 64, 903-912.

Benjamin, R. S, Costello, E. J., and Warren, M. (1990). Anxiety disorders in a pediatric sample. J. Anxiety Disord. 4,293-316.

Bergman, K., Sarkar, P., Glover, V., and O'Connor, T. G. (2010). Maternal prenatal cortisol and infant cognitive development: moderation by infantmother attachment. Biol. Psychiatry 67, 1026-1032.

Biederman, J., Rosenbaum, J. F., BolducMurphy, E. A., Faraone, S. V., Chaloff, J., Hirshfeld, D. R., and Kagan, J. (1993). A three-year follow-up of children with and without behavioral inhibition. J. Am. Acad. Child Psychiatry 32, 814-821.

Bishop, S. J. (2007). Neurocognitive mechanisms of anxiety: an integrative account. Trends Cogn. Sci. 11, 307-316.

Bittner, A., Egger, H. L., Erkanli, A., Costello, E. J., Foley, D. L., and Angold, A. (2007). What do childhood anxiety disorders predict? J. Child Psychol. Psychiatry 48, 1174-1183.

Boelen, P. A., and Reijntjes, A. (2009). Intolerance of uncertainty and social anxiety. J. Anxiety Disord. 23, 130-135.

Bögels, S. M., and Brechman-Toussaint, M. L. (2006). Family issues in child anxiety: attachment, family functioning, parental rearing and beliefs. Clin. Psychol. Rev. 26, 834-856.

Bögels, S. M., and Phares, V. (2008). Fathers' role in the etiology, prevention and treatment of child anxiety: a review, and new model. Clin. Psychol. Rev. 28, 539-558.

Bögels, S. M., and Tarrier, N. (2004). Unexplored issues and future directions in social phobia research. Clin. Psychol. Rev. 24, 731-736.

Bokhorst, C. L., BakermansKranenburg, M. J., Fearon, R. M., van Ijzendoorn, M. H., Fonagy, P., and Schuengel, C. (2003). The importance of shared environment in mother-infant attachment security: a behavioral genetic study. Child Dev. 74, 1769-1782.

Bosquet, M., and Egeland, B. (2006). The development and maintenance of anxiety symptoms from infancy through adolescence in a longitudinal sample. Dev. Psychopathol. 18, 517-550.

Bowlby, J. (1973). Attachment and Loss: Vol. 2. Separation: Anxiety and Anger. New York: Basic Books.

Bremner, J. D., Randall, P., Scott, T., Bronen, R., Soutwick, S., Delaney, R. C., McCarthy, G., Charney, D. S., and Innis, R. B. (1995). MRI-based measurement of hippocampal volume in patients with posttraumatic stress disorder. Am. J. Psychiatry 152, 973-981.

Bretherton, I., and Munholland, K. A. (2008). "Internal working models in attachment relationships: elaborating a central construct in attachment theory," in Handbook of Attachment:
Theory, Research, and Clinical Applications, 2nd Edn, eds J. Cassidy and P. R. Shaver (New York: Guilford Press), 102-127.

Breton, J., Bergeron, L., Valla, J., Berthiaume, C., Gaudet, N., Lambert, J., St-Georges, M., Houde, L., and Lépine, S. (1999). Quebec child mental health survey: prevalence of DSM-III-R mental health disorders. J. Child. Psychol. Psychiatry 40 , 375-384.

Brisch, K. H., Bechinger, D., Betzler, S. and Heinemann, H. (2003). Early preventive attachment-oriented psychotherapeutic intervention program with parents of a very low birthweight premature infant: results of attachment and neurological development. Attach. Hum. Dev. $5,120-135$.

Britton, J. C., Lissek, S., Grillon, C., Norcross, M. A., and Pine, D. S. (2011). Development of anxiety: the role of threat appraisal and fear learning. Depress. Anxiety 28, 5-17.

Brussoni, M. J., Jang, K. L., Livesley, J., and MacBeth, T. M. (2000) Genetic and environmental influences on adult attachment styles. Pers. Relatsh. 6, 283-289.

Buchheim, A., Heinrichs, M., George, C., Pokorny, D., Koops, E., Henningsen, P., O'Connor, M. F., and Gündel, H. (2009). Oxytocin enhances the experience of attachment security. Psychoneuroendocrinology 34, 1417-1422.

Buss, C., Lord, C., Wadiwalla, M., Hellhammer, D. H., Lupien, S. J., Meaney, M. J., and Pruessner, J. C. (2007). Maternal care modulates the relationship between prenatal risk and hippocampal volume in women but not in men. J. Neurosci. 27, 2592-2595.

Calkins, S., and Fox, N. (1992). The relations between infant temperament, security of attachment and behavioral inhibition at 24 months. Child Dev. 63, 1456-1472.

Campbell, L., Simpson, J. A., Boldry, J., and Kashy, D. A. (2005). Perceptions of conflict and support in romantic relationships: the role of attachment anxiety. J. Soc. Psychol. 88, 510-531.

Campbell-Sills, L., Simmons, A. N., Lovero, K. L., Rochlin, A. A., Paulus, M. P., and Stein, M. B. (2010). Functioning of neural systems supporting emotion regulation in anxietyprone individuals. Neuroimage 54 689-696.

Canino, G., Shrout, P. E., Rubio-Stipec, M., Bird, H. R., Bravo, M., Ramirez, R., Chavez, L., Alegria, M., Bauermeister, J. J., Hohmann, A., Ribera, J., Garcia, P., and Martinez-Taboas,
A. (2004). The DSM-IV rates of child and adolescent disorders in Puerto Rico. Arch. Gen. Psychiatry 61, 85-93.

Capitanio, J., Mendoza, S., Mason, W., and Manninger, N. (2005). Rearing environment and hypothalamicpituitary-adrenal regulation in young rhesus monkeys (Macaca mulatta). Dev. Psychobiol. 2005, 46, 318-330.

Carlson, E. A., and Sroufe, L. A. (1995). "The contribution of attachment theory to developmental psychopathology," in Developmental Processes and Psychopathology, Vol. 1, Theoretical Perspectives and Methodological Approaches, eds D. Cicchetti and D. J. Cohen (New York: Wiley), 581-617.

Caspi, A., Moffit, T. E., Newman, D. L., and Silva, P. A. (1996). Behavioural observations at age 3 years predict adult psychiatric disorders. Arch. Gen. Psychiatry 53, 1033-1039.

Cassidy, J. (1995). "Attachment and generalized anxiety disorder," in Emotion, Cognition, and Representation. Rochester Symposium on Developmental Psychopathology, Vol. 6, eds D. Cicchetti and S. L. Toth, (Rochester, NY: University of Rochester Press), 343-370.

Cassidy, J., and Berlin, L. (1994). The insecure/ambivalent pattern of attachment: theory and research. Child Devel. 65, 971-991.

Cassidy, J., and Kobak, R.R. (1988). "Avoidance and its relationship with other defensive processes," in Clinical Implications of Attachment, eds J. Belsky and T. Nezworski (Hillsdale, NJ: Erlbaum), 300-323.

Chorpita, B. F., and Barlow, D. H. (1998). The development of anxiety: the role of control in the early environment. Psychol. Bull. 124, 3-21.

Chrousos, G. P. (2009). Stress and disorders of the stress system. Nat. Rev. Endocrinol. 5, 374-381.

Cicchetti, D. (2010). Resilience under conditions of extreme stress: a multilevel perspective. World Psychiatry 9, 145-154.

Cicchetti, D., and Rogosch, F. A. (1996). Equifinality and multifinality in developmental psychopathology. Dev. Psychopathol. 8, 597-600.

Cicchetti, D., and Rogosch, F. A. (1997). The role of self-organization in the promotion of resilience in maltreated children. Dev. Psychopathol. 9, 797-815

Clark, L. A., and Watson, D. (1991). Tripartite model of anxiety and depression: evidence and taxonomic implications. J. Abnorm. Psychol. 100, 316-336. 
Colonnesi, C., Draijer, E. M., Stams, G. J. J. M, Van der Bruggen, C. O., Bögels, S. M., and Noon, M. J. (2011). The relation between insecure attachment and child anxiety: a meta-analytic review. J. Clin. Child Adolesc. Psychol. 40, 630-645.

Cooper, J., Fearn, V., Willetts, L., Seabrook, H., and Parksinson, M. (2006). Affective disorder in the parents of a clinic sample of children with anxiety disorders. J. Affect. Disord. 93, 205-212.

Costello, E., Mustillo, S., Erkanli, A., Keeler, G., and Angold, A. (2003). Prevalence and development of psychiatric disorders in childhood and adolescence. Arch. Gen. Psychiatry 60, 837-844.

Craske, M., Rauch, S., Ursano, R., Prenoveau, J., Pine, D., and Zinbarg, R. (2009). What is an anxiety disorder? Depress Anxiety 26, 1066-1085.

Crawford, T. N., Livesley, W. J., Jang, K. L., Shaver, P. R., Cohen, P., and Ganiban, J. (2007). Insecure attachment and personality disorder: a twin study of adults. Eur. J. Pers. 21, 191-208.

Creswell, C., and Cartwright-Hatton, S. (2007). Family treatment of child anxiety: outcomes, limitations and future directions. Clin. Child Fam. Psychol. Rev. 10, 232-252.

Creswell, C., Willetts, L., Murray, L., Singhal, M., and Cooper, P. (2008). Treatment of child anxiety: an exploratory study of the role of maternal anxiety and behaviors in treatment outcome. Clin. Psychol. Psychother. 15, 38-44.

Crockenberg, S., and McCluskey, K. (1986). Change in maternal behavior during the baby's first year of life. Child Dev. 57, 746-753.

Crowell, J., and Feldman, S. S. (1991). Mothers' working models of attachment relationships and mother and child behavior during separation and reunion. Dev. Psychol. 27, 597-605.

Davidson, R. J., Shackman, A. J., and Maxwell, J. S. (2004). Asymmetries in face and brain related to emotion. Trends Cogn. Sci. 8, 389-391.

De Bellis, M. D., Baum, A. S., Birmaher, B., Keshavan, M. D., Eccard, C. H., Boring, A. M., Jenkins, F. J., and Ryan, N. D. (1999). Developmental traumatology. Part I: biological stress systems. Biol. Psychiatry 45, 1259-1270.

De Bellis, M. D., Chrousos, G. P., Dorn, L. D., Burke, L., Helmers, K., Kling, M. A., Trickett, P. K., and Putnam, F. W. (1994). Hypothalamicpituitary-adrenal axis dysregulation in sexually abused girls. J. Clin. Endocrinol. Metab. 78, 249-255.

De Bolle, M., and De Fruyt, F. (2010). The tripartite model in childhood and adolescence: future directions for developmental research. Child Dev. Perspect. 4, 174-180.

De Kloet, E. R., Sibug, R. M., Helmerhorst, F. M., and Schmidt, M. V. (2005). Stress, genes and the mechanism of programming the brain for later life. Neurosci. Biobehav. Rev. 29, 271-281.

DeRuiter, C., and van Ijzendoorn, M. H. (1992). Agoraphobia and anxiousambivalent attachment: an integrated review. J. Anxiety Disord. 6, 365-381.

Diamond, L. M., and Aspinwall, L. G. (2003). Emotion regulation across the life span: an integrative perspective emphasizing self-regulation, positive affect, and dyadic processes. Motiv. Emot. 27, 125-156.

Diamond, L. M., Hicks, A. M., and Otter-Henderson, K. D. (2008). Every time you go away: changes in affect, behavior, and physiology associated with travel-related separations from romantic partners. J. Pers. Soc. Psychol. 95, 385-403.

DiBartolo, P. M., and Helt, M. (2007). Theoretical models of affectionate versus affectionless control in anxious families: a critical examination based on observations of parentchild interactions. Clin. Child Fam. Psychol. Rev. 10, 253-274.

Dick, A., Vanderbilt, S., Jacot, C., Hurni, F., Jäggi, C., and Leiggener, E. (2005). Erinnertes elterliches Erziehungsverhalten und aktuelle Bindungsorganisation im Erwachsenenalter: Unterschiede zwischen Personen mit und ohne Angststörungen. Z. Klein. Psychol. 34, 35-38.

Ditzen, B., Schaer, M., Gabriel, B., Bodenmann, G., Ehlert, U., and Heinrichs, M. (2009). Intranasal oxytocin increases positive communication and reduces cortisol levels during couple conflict. Biol. Psychiatry $65,728-731$.

Ditzen, B., Schmidt, S., Strauss, B., Nater, U. M., Ehlert, U., and Heinrichs, M. (2008). Adult attachment and social support interact to reduce psychological but not cortisol responses to stress. J. Psychosom. Res. 64, 479-486.

Dozier, M., Lindhiem, O., Lewis, E., Bick, J., Bernard, K., and Peloso, E. (2009). Effects of a foster parent training program on young children's attachment behaviors: preliminary evidence from a randomized clinical trial. Child Adolesc. Social Work J. 26, 321-332.
Edmiston, E., Wang, F., Mazure, C. M., Guiney, J., Sinha, R., and Blumberg, H. P. (in press). Corticostriatallimbic gray matter morphology in adolescents with self-reported exposure to childhood maltreatment. Arch. Pediatr. Adolesc. Med.

Ehringer, M. A., Rhee, S. H., Young, S. E., Corley, R. P., and Hewitt, J. K. (2006). Genetic and environmental contributions to common psychopathologies of childhood and adolescence: a study of twins and their siblings. J. Abnorm. Child Psychol. Available at: http://dx. doi.org/10.1007/s10802-005-9000-0

Ein-Dor, T., Mikulincer, M., Doron, G., and Shaver, P. R. (2010). The attachment paradox: how can so many of us (the insecure ones) have no adaptive advantages? Perspect. Psychol. Sci. 5, 123-141.

Eisenberger, N. I., Taylor, S. E., Gable, S. L., Hilmert, C. J., and Lieberman, M. D. (2007). Neural pathways link social support to attenuated neuroendocrine stress responses. $\mathrm{Neu}$ roimage 35, 1601-1612.

Eley, T. C., Bolton, D., O'Connor, T. G., Perrin, S., Smith, P., and Plomin, R. (2003). A twin study of anxietyrelated behaviours in pre-school children. J. Child Psychol. Psychiatry 44,7 .

Eley, T. C., Napolitano, M., Lau, J. Y. F., and Gregory, A. M. (2010). Does childhood anxiety evoke maternal control? A genetically informed study. J. Child Psychol. Psychiatry 51, 772-779.

Ellenbogen, M. A., Schwartzman, A. E., Stewart, J., and Walker, C. D. (2002). Stress and selective attention: the interplay of mood, cortisol levels, and emotional information processing. Psychophysiology 39, 723-732.

Etkin, A. (2010). "Functional neuroanatomy of anxiety: a neural circuit perspective," in Behavioral Neurobiology of Anxiety and Its Treatment, eds M. B. Stein and T. Steckler (New York: Springer), 251-278.

Etkin, A., Klemenhagen, K. C., Dudman, J. T., Rogan, M. T., Hen, R., Kandel, E. R., and Hirsch, J. (2004). Individual differences in trait anxiety predict the response of the basolateral amygdala to unconsciously processed fearful faces. Neuron 44 , 1043-1055.

Etkin, A., and Wager, T. D. (2007). Functional neuroimaging of anxiety: a meta-analysis of emotional processing in PTSD, social anxiety disorder, and specific phobia. Am. J. Psychiatry 7, 164, 1476-1488.
Fearon, R. M. P., van Ijzendoorn, M. H., Fonagy, P., Bakermans-Kranenburg, M. J., Schuengel, C., and Bokhorst C. L. (2006). In search of shared and nonshared environmental factors in security of attachment: a behavior-genetic study of the association between sensitivity and attachment security. Dev. Psychol. 42, 1026-1040.

Feldman, R., Weller, A., ZagoorySharon, O., and Levine, A. (2007). Evidence for a neuroendocrinological foundation of human affiliation: plasma oxytocin levels across pregnancy and the postpartum period predict mother-infant bonding. Psychol. Sci. 18, 965-970.

Fonagy, P. (1998). An attachment theory approach to treatment of the difficult patient. Bull. Menninger Clin. 62, 147-169.

Fonagy, P., Gergely, G., Jurist, E. L., and Target, M. (2002). Affect Regulation, Mentalization, and the Development of the Self. New York: Other Press.

Fonagy, P., Gergely, G., and Target, M. (2007). The parent-infant dyad and the construction of the subjective self. J. Child Psychol. Psychiatry 48, 288-328.

Fonagy, P., Leigh, T., Steele, M., Steele, H., Kennedy, R., Mattoon, G., Target, M., and Gerber, A. (1996). The relation of attachment status, psychiatric classification, and response to psychotherapy. J. Consult. Clin. Psychol. 64, 22-31.

Fonagy, P., and Luyten, P. (2009). A developmental, mentalization-based approach to the understanding and treatment of borderline personality disorder. Dev. Psychopathol. 21, 1355-1381.

Fonagy, P., and Target, M. (1997). Attachment and reflective function: their role in self-organization. Dev. Psychopathol. 9, 679-700.

Ford, T., Goodman, R., and Meltzer, H. (2003). The British child and adolescent mental health survey 1999: the prevalence of DSM-IV disorders. J. Am. Acad. Child Adolesc. Psychiatry 42, 1203-1211.

Fox, N. A., Hane, A. A., and Pine, D. S. (2007). Plasticity for affective neurocircuitry: how the environment affects gene expression. Curr. Dir. Psychol. Sci. 16, 1-5.

Fox, N. A., Henderson, H. A., Rubin, K. H., Calkins, S. D., and Schmidt, L. A. (2001). Continuity and discontinuity of behavioral inhibition and exuberance: psychophysiological and behavioral influences across the first four years of life. Child Dev. $72,1-21$. 
Fraley, R. C., Niedenthal, P. M., Marks, M., Brumbaugh, C., and Vicary, A. (2006). Adult attachment and the perception of emotional expressions: probing the hyperactivating strategies underlying anxious attachment. J. Pers. 74, 1163-1190.

Francis, D., Diorio, J., Liu, D., and Meaney, M. J. (1999). Nongenomic transmission across generations of maternal behavior and stress responses in the rat. Science 286, 1155-1158.

Fredrickson, B. L. (2001). The role of positive emotions in positive psychology. The broaden-and-build theory of positive emotions. Am. Psychol. 56, 218-226.

Frith, C. D., and Frith, U. (2006). The neural basis of mentalizing. Neuron 50, 531-534.

Gallagher, H. L., and Frith, C. D. (2003). Functional imaging of 'theory of mind'. Trends Cogn. Sci. 7, 77-83.

Ganzel, B. L., Morris, P. A., and Wethington, E. (2010). Allostasis and the human brain: integrating models of stress from the social and life sciences. Psychol. Rev. 117, 134-174.

Gerull, F. C., and Rapee, R. M. (2002). Mother knows best: effects of maternal modelling on the acquisition of fear and avoidance behaviour in toddlers. Behav. Res. Ther. 40, 279-287.

Ghera, M. M., Hane, A. A., Malesa, E. M., and Fox, N. A. (2006). The role of infant soothability in the relation between infant negativity and maternal sensitivity. Infant Behav. Dev. 29, 289-293.

Gillath, O., Bunge, S. A., Shaver, P. R., Wendelken, C., and Mikulincer, M. (2005). Attachment-style differences in the ability to suppress negative thoughts: exploring the neural correlates. Neuroimage 28, 835-847.

Ginsburg, G., and Schlossberg, M. C. (2002). Family-based treatment ofchildhood anxiety disorders. Int. J. Psychiatry 14, 142-153.

Gluckman, P. D., Hanson, M. A., and Beedle, A. S. (2007). Non-genomic transgenerational inheritance of disease risk. Bioessays 29, 145-154.

Goodyer, I. M., Wright, C., and Altham, P. M. E. (1988). Maternal adversity and recent stressful life events in anxious and depressed children. J. Child Psychol. Psychiatry 29, 651-667.

Gordon, I., Zagoory-Sharon, O., Schneiderman, I., Leckman, J. F., Weller, A., and Feldman, R. (2008). Oxytocin and cortisol in romantically unattached young adults: associations with bonding and psychological distress. Psychophysiology 45, 349-352.

Gould, E., McEwen, B., Tanapat, P., Galea, L. A., and Fuchs, E. (1997).
Neurogenesis in the dentate gyrus of the adult tree shrew is regulated by psychosocial stress and NMDA receptor activation. J. Neurosci. 17, 2492-2498.

Graham, Y. P., Heim, C., Goodman, S. H., Miller, A. H., and Nemeroff, C. B. (1999). The effects of neonatal stress on brain development: implications for psychopathology. Dev. Psychopathol. 11, 545-565.

Gray, J. A., and McNaughton, N. (2000). The Neuropsychology of Anxiety: An Enquiry into the Functions of the Septo-Hippocampal System. New York: Oxford University Press.

Green, J. G., McLaughlin, K. A., Berglund, P. A., Gruber, M. J., Sampson, N. A., Zaslavsky, A. M., and Kessler, R. C. (2010). Childhood adversities and adult psychiatric disorders in the national comorbidity survey replication I: associations with first onset of DSM-IV disorders. Arch. Gen. Psychiatry 67, 113-123.

Gregory, A. M., and Eley, T. C. (2007). Genetic influences on anxiety in children: what we've learned and where we're heading. Clin. Child Fam. Psychol. Rev. 10, 199-212.

Grillon, C. (2002). Startle reactivity and anxiety disorders: aversive conditioning, context, and neurobiology. Biol. Psychiatry 52, 958-975.

Gross, C., and Hen, R. (2004). The developmental origins of anxiety. Nat. Rev. Neurosci. 5, 545-552.

Grossmann, K. E., Grossmann, K., and Waters, E. (eds). (2005). The Power of Longitudinal Attachment Research: From Infancy and Childhood to Adulthood. New York: Guilford.

Grossmann, K. E., Grossmann, K., and Waters, E. (2006). Attachment from Infancy to Adulthood: The Major Longitudinal Studies. New York: Guilford.

Gunnar, M., and Quevedo, K. (2007). The neurobiology of stress and development. Annu. Rev. Psychol. 58, 145-173.

Gunnar, M. R., Brodersen, L., Nachmias, M., Buss, K., and Rigatuso, J. (1996). Stress reactivity and attachment security. Dev. Psychobiol. 29, 191-204.

Gunnar, M. R., and Donzella, B. (2002). Social regulation of the cortisol levels in early human development. Psychoneuroendocrinology 27, 199-220.

Gunnar, M. R., Quevedo, K. M. E., De Kloet, M. S. O., and Eric, V. (2007). Early care experiences and HPA axis regulation in children: a mechanism for later trauma vulnerability. Prog. Brain Res. 167, 137-149.
Hane, A. A., and Fox, N. A. (2006). Ordinary variations in maternal caregiving of human infants influence stress reactivity. Psychol. Sci. 17, 550-556.

Hane, A. A., Fox, N. A., Henderson, H. A., and Marshall, P. J. (2008). Behavioral reactivity and approachwithdrawal bias in infancy. Dev. Psychol. 44, 1491-1496.

Hane, A. A., Henderson, H. A., Reeb-Sutherland, B. C., and Fox, N. A. (2010). Ordinary variations in human maternal caregiving in infancy and biobehavioral development in early childhood: a follow-up study. Dev. Psychobiol. 52, 558-567.

Hauser, S. T., Allen, J. P., and Golden, E. (2006). Out of the Woods: Tales of Resilient Teens. Cambridge: Harvard University Press.

Heim, C., and Nemeroff, C. B. (2001) The role of childhood trauma in the neurobiology of mood and anxiety disorders: preclinical and clinical studies. Biol. Psychiatry 49, 1023-1039.

Heim, C., Newport, D. J., Mletzko, T., Miller, A. H., and Nemeroff, C. B. (2008). The link between childhood trauma and depression: insights from HPA axis studies in humans. Psychoneuroendocrinology 33, 693-710.

Heim, C., Plotsky, P. M., and Nemeroff, C. B. (2004). Importance of studying the contributions of early adverse experience to neurobiological findings in depression. Neuropsychopharmacology 29, 641-648.

Heim, C., Young, L. J., Newport, D. J., Mletzko, T., Miller, A. H., and Nemeroff, C. B. (2009). Lower CSF oxytocin concentrations in women with a history of childhood abuse. Mol. Psychiatry 10, 954-958.

Heinrichs, M., Baumgartner, T., Kirschbaum, C., and Ehlert, U. (2003). Social support and oxytocin interact to suppress cortisol and subjective responses to psychosocial stress. Biol. Psychiatry 54, 1389-1398.

Heinrichs, M., and Domes, G. (2008). Neuropeptides and social behaviour: effects of oxytocin and vasopressin in humans. Prog. Brain Res. 170, 337-350.

Hettema, J. M., Carol, A., Prescott, C. A., Myers, J. M., Michael, C., Neale, M. C., and Kendler, K. S. (2005). The structure of genetic and environmental risk factors for anxiety disorders in men and women. Arch. Gen. Psychiatry 62, 182-189.

Hettema, J. M., Neale, M. C., and Kendler, K. S. (2001). A review and meta-analysis of the genetic epidemiology of anxiety disorders. Am. J. Psychiatry 158, 1568-1578.
Hirshfeld, D. R., Biederman, J., Brody, L., Faraone, S. V., and Rosenbaum, J. F. (1997). Expressed emotion toward children with behavioral inhibition: associations with maternal anxiety disorder. J. Am. Acad. Child Adolesc. Psychiatry 36, 910-917.

Hirshfeld, D. R., Rosenbaum, J. F., Biederman, J., Bolduc, E. A., Faraone, S. V., Snidman, N., Reznick, J. S., and Kagan, J. (1992). Stable behavioral inhibition and its association with anxiety disorder. J. Am. Acad. Child Psychiatry 31, 103-111.

Holaway, R. M., Heimberg, R. G., and Coles, M. E. (2006). A comparison of intolerance of uncertainty in analogue obsessive-compulsive disorder and generalized anxiety disorder. J. Anxiety Disord. 20, 158-174.

Hudson, J. L., and Rapee, R. M. (2002). Parent-child interactions in clinically anxious children and their siblings. J. Clin. Child Adolesc. Psychol. 31, 548-555.

Huizink, A. C., Mulder, E. J. H., and Buitelaar, J. K. (2004). Prenatal stress and risk for psychopathology: specific effects or induction of general susceptibility? Psychol. Bull. 130, 115-142.

Insel, T. R. (2010). The challenge of translation in social neuroscience: a review of oxytocin, vasopressin, and affiliative behavior. Neuron 65, 768-779.

Izquierdo, A., Wellman, C. L., and Holmes, A. (2006). Brief uncontrollable stress causes dendritic retraction in infralimbic cortex and resistance to fear extinction in mice. $J$. Neurosci. 26, 5733-5738.

Jackowski, A. P., Douglas-Palumberi, H., Jackowski, M., Win, L., Schultz, R. T., Staib, L. W., Krystal, J. H., and Kaufman, J. (2008). Corpus callosum in maltreated children with posttraumatic stress disorder: a diffusion tensor imaging study. Psychiatry Res. 162, 256-261.

Joels, M., and Baram, T. Z. (2009). The neuro-symphony of stress. Nat. Rev. Neurosci. 10, 459-466.

Johnson, L. R., Hou, M., Prager, E. M., and LeDoux, J. E. (2011). Regulation of the fear network by mediators of stress: norepinephrine alters the balance between cortical and subcortical afferent excitation of the lateral amygdala. Front. Behav. Neurosci. 5:23. doi: 10.3389/fnbeh.2011.00023 Joraschky, P., and Petrowski, K. (2008). "Angst und Bindung," in Bindung und Psychopathologie, ed. B. Strauß(Stuttgart: Klett-Cotta), 49-80. 
Kagan, J., Reznick, J. S., and Snidman, N. (1988). Biological bases of childhood shyness. Science 240, 167-171.

Kallen, V. L., Tulen, J. H., Utens, E. M., Treffers, P. D., De Jong, F. H., and Ferdinand, R. F. (2008). Associations between HPA axis functioning and level of anxiety in children and adolescents with an anxiety disorder. Depress. Anxiety 25, 131-141.

Kaufman, J., Birmaher, B., Perel, J., Dahl, R. E., Moreci, P., Nelson, B., Wells, W., and Ryan, N. D. (1997). The corticotropin-releasing hormone challenge in depressed abused, depressed nonabused, and normal control children. Biol. Psychiatry 42, 669-679.

Kendall, P. C., Brady, E. U., and Verduin, T. L. (2001). Comorbidity in childhood anxiety disorders and treatment out- come. J. Am. Acad. Child Adolesc. Psychiatry 40, 787-794.

Kendall, P. C., Hudson, J. L., Gosch, E., Flannery-Schroeder, E., and Suveg, C. (2008). Cognitive behavioral therapy for anxiety disordered youth: a randomized clinical trial evaluating child and family modalities. J. Consult. Clin. Psychol. 76, 282-297.

Kessler, R. C. (2004). The epidemiology of dual diagnosis. Biol. Psychiatry 56, 730-737.

Kessler, R. C., Ruscio, A. M., Shear, K., and Wittchen, H. (2010). Epidemiology of anxiety disorders. Curr. Top. Behav. Neurosci. 2, 21-35.

Kessler, R. C., and Wang, P. S. (2008). The descriptive epidemiology of commonly occurring mental disorders in the united states. Annu. Rev. Public Health 29, 115-129.

Kim, K. J., Conger, R. D., Elder, G. H. Jr., and Lorenz, F. O. (2003). Reciprocal influences between stressful life events and adolescent internalizing and externalizing problems. Child Dev. 74, 127-143.

Kim, M. J., Gee, D. G., Loucks, R. A., Davis, F. C., and Whalen, P. J. (2011). Anxiety dissociates dorsal and ventral medial prefrontal cortex functional connectivity with the amygdala at rest. Cereb. Cortex 21, 1667-1673.

Kim, M. J., and Whalen, P. J. (2009). The structural integrity of an amygdala-prefrontal pathway predicts trait anxiety. J. Neurosci. 29, 11614-11618.

Kirsch, P., Esslinger, C., Chen, Q., Mier, D., Lis, S., Siddhanti, S., Gruppe, H., Mattay, V. S., Gallhofer, B., and Meyer-Lindenberg, A. (2005). Oxytocin modulates neural circuitry for social cognition and fear in humans. J. Neurosci. 25, 11489-11493.
Kirschbaum, C., Klauer, T., Filipp, S., and Hellhammer, D. H. (1995). Sexspecific effects of social support on cortisol and subjective responses to acute psychological stress. Psychosom. Med. 57, 23-31.

Kobak, R., Cassidy, J., and Ziv, Y. (2004). "Attachment-related trauma and posttraumatic stress disorder: implications for adult adaptation," in Adult Attachment: Theory, Research, and Clinical Implications, ed. W. S. Rholes (New York: Guilford Publications, Inc.), 388-407.

Kober, H., Barrett, L. F., Joseph, J., BlissMoreau, E., Lindquist, K., and Wager, T. D. (2008). Functional grouping and cortical-subcortical interactions in emotion: a metaanalysis of neuroimaging studies. Neuroimage 42, 998-1031.

Krueger, R. F., Skodol, A. E., Livesley, W. J., Shrout, P. E., and Huang, Y. (2007). Synthesizing dimensional and categorical approaches to personality disorders: refining the research agenda for DSM-V Axis II. Int. J. Methods Psychiatr. Res. 16, S65-S73.

Kubzansky, L., Mendes, W. B., Aplleton, A., Block, J., and Adler, G. K. (2009). Protocol for an experimental investigation of the roles of oxytocin and social support in neuroendocrine, cardiovascular, and subjective responses to stress across age and gender. BMC Public Health 9, 481. doi: 10.1186/1471-2458-9-481

Kudielka, B. M., and Kirschbaum, C. (2005). Sex differences in HPA axis responses to stress: a review. Biol. Psychol. 69, 113-132.

LaBar, K. S., and Cabeza, R. (2006). Cognitive neuroscience of emotional memory. Nat. Rev. Neurosci. 54, 54-64.

LaBar, K. S., and Phelps, E. A. (2005).Reinstatement of conditioned fear in humans is context-dependent and impaired in amnesia. Behav. Neurosci. 119, 677-686.

Last, C. G., Perrin, S., Hersen, M., and Kazdin, A. E. (1996). A prospective study of childhood anxiety disorders. J. Am. Acad. Child Adolesc. Psychiatry 35, 1502-1510.

Last, C. G., Strauss, C. C., and Francis, G. (1987). Comorbidity among childhood anxiety disorders. J. Nerv. Ment. Dis. 175, 726-730.

LeDoux, J. E. (1996). The Emotional Brain. New York, NY: Simon \& Schuster.

LeDoux, J. E. (2000). Emotion circuits in the brain. Annu. Rev. Neurosci. 23 , 155-184.
Lee, A., and Hankin, B. L. (2009). Insecure attachment, dysfunctional attitudes, and low self-esteem predicting prospective symptoms of depression and anxiety during adolescence. J. Clin. Child Adolesc. Psychol. 38, 219-231.

Lemche, E., Kreppner, J. M., Joraschky, P., and Klann-Delius, G. (2007). Attachment organization and the early development of internal state language: a longitudinal perspective. Int. J. Behav. Dev. 31, 252-262.

Lépine, J. (2002). The epidemiology of anxiety disorders: prevalence and societal costs. J. Clin. Psychiatry 63, 4-8.

Lieberman, M. D. (2007). Social cognitive neuroscience: a review of core processes. Annu. Rev. Psychol. 58, 259-289.

Luijk, M. P. C. M., Saridjan, N., Tharner, A., van Ijzendoorn, M. H., Bakermans-Kranenburg, M. J. Jaddoe, V. W., Hofman, A., Verhulst, F. C., and Tiemeier, H. (2010). Attachment, depression, and cortisol: deviant patterns in insecureresistant and disorganized infants. Dev. Psychobiol. 52, 441-452.

Lupien, S. J., McEwen, B. S., Gunnar, M. R., and Heim, C. (2009). Effects of stress throughout the lifespan on the brain, behaviour and cognition. Nat. Rev. Neurosci. 10, 434-445.

Luyten, P., and Blatt, S. J. (2011). Integrating theory-driven and empirically-derived models of personality development and psychopathology: a proposal for DSM V. Clin. Psychol. Rev. 31, 52-68.

Luyten, P., Vliegen, N., Van Houdenhove, B., and Blatt, S. J. (2008). Equifinality, multifinality, and the rediscovery of the importance of early experiences: pathways from early adversity to psychiatric and (functional) somatic disorders. Psychoanal. Study Child 63, 27-60.

MacLeod, C., Rutherford, E., Campbell, L., Ebsworth, G., and Holker, L. (2002). Selective attention and emotional vulnerability: assessing the causal basis of their association through the experimental manipulation of attentional bias. J. Abnorm. Psychol. 111, 107-123.

Main, M., and Hesse, E. (1990). "The disorganized/disoriented pattern in infancy: precursors and sequelae," in Attachment in the Preschool Years: Theory, Research and Intervention, eds M. Greenberg, D. Cicchetti, and E. M. Cummings (Chicago: University of Chicago Press), 161-184.

Main, M., and Solomon, J. (1986). "Discovery of an insecuredisorganized/disoriented attachment pattern," in Affecfive Development in Infancy, eds T. B. Brazelton and M. W. Yogman (Norwood, NJ: Ablex), 95-124.

Manassis, K., Bradley, S., Goldberg, S., Hood, J., and Swinson, R. P. (1994). Attachment in mothers with anxiety disorders and their children. J. Am. Acad. Child Psychiatry 33, 1106-1113.

Martin, E. I., Ressler, K. J., Binder, E., and Nemeroff, C. B. (2009). The neurobiology of anxiety disorders: brain imaging, genetics, and psychoneuroendocrinology. Psychiatr. Clin. North Am. 32, 549-575.

Masten, A. S., and Obradovic, J. (2008). Disaster preparation and recovery: lessons from research on resilience in human development. Ecol. Society 13,9 .

Mathew, S. J., Price, R. B., and Charney, D. S. (2008). Recent advances in the neurobiology of anxiety disorders: implications for novel therapeutics. Am. J. Med. Genet. C Semin. Med. Genet. 148, 89-98.

Matthews, S. G. (2002). Early programming of the hypothalamopituitary-adrenal axis. Trends Endocrinol. Metab. 13, 373-380.

Mayes, L. C. (2006). Arousal regulation, emotional flexibility, medial amygdala function, and the impact of early experience: comments on the paper of Lewis et al. Ann. N. Y. Acad. Sci. 1094, 178-192.

McCormick, C. M., Smythe, J. W., Sharma, S., and Meaney, M. J. (1995). Sex-specific effects of prenatal stress on hypothalamic-pituitaryadrenal responses to stress and brain glucocorticoid receptor density in adult rats. Dev. Brain Res. 84, 55-61.

McCrory, E., De Brito, S. A., and Viding, E. (2010). Research review: the neurobiology and genetics of maltreatment and adversity. J. Child Psychol. Psychiatry 51, 1079-1095.

McEwen, B. S. (2007). The physiology and neurobiology of stress and adaptation, central role of the brain. Physiol. Rev. 87, 873-904.

McEwen, B. S., and Gianaros, P. J. (2010). Central role of the brain in stress and adaptation: links to socioeconomic status, health, and disease. Ann. N. Y. Acad. Sci. 1186, 190-222.

McGowan, P. O., Sasaki, A., D’Alessio, A. C., Dymov, S., Labonté, B., Szyf, M., Turecki, G., and Meaney, M. J. (2009). Epigenetic regulation of the glucocorticoid receptor in human brain associates with childhood abuse. Nat. Neurosci. 12, 342-348. 
McLeod, B. D., Wood, J. J., and Weisz, J. R. (2007). Examining the association between parenting and childhood anxiety: a meta-analysis. Clin. Psychol. Rev. 27, 155-172.

Meaney, M. (2010). Vention on intellectual and academic achievement: a follow-up study of children from low-income families. Epigenetics and the biological definition of gene $\mathrm{x}$ environment interactions. Child Dev. 81, 41-79.

Meaney, M. J., Diorio, J., Francis, D., Widdowson, J., LaPlante, P., Caldji, C., Sharma, S., Seckl, J. R., and Plotsky, P. M. (1996). Early environmental regulation of forebrain glucocorticoid receptor gene expression: implications for adrenocortical responses to stress. Dev. Neurosci. 18, 49-72.

Meaney, M. J., Szyf, M., and Seckl, J. R. (2007). Epigenetic mechanisms of perinatal programming of hypothalamic-pituitary-adrenal function and health. Trends Mol. Med. 13, 269-277.

Meins, E., Fernyhough, C., Wainwright, R., Das Gupta, M., Fradley, E., and Tuckey, M. (2002). Maternal mind-mindedness and attachment security as predictors of theory of mind understanding. Child Dev. 73, 1715-1726.

Mikulincer, M., and Shaver, P. R. (2005). Attachment theory and emotions in close relationships: exploring the attachment-related dynamics of emotional reactions to relational events. Pers. Relatsh. 2, 149-168.

Mikulincer, M., and Shaver, P. R. (2007). Attachment in Adulthood: Structure, Dynamics, and Change. New York: Guilford Press.

Mikulincer, M., and Shaver, P. R. (2008). "Adult attachment and affect regulation," in Hadbook of Atachment: Theory, Research and Clinical Applications, eds J. Cassidy and P. R. Shaver (New York: Guilford Publications), 503-531.

Mikulincer, M., and Shaver, P. R. (2009). An attachment and behavioral systems perspective on social support. J. Soc. Pers. Relat. 26, 7-19.

Mikulincer, M., Shaver, P. R., Bar-On, N., and Ein-Dor, T. (2010). The pushes and pulls of close relationships: attachment insecurities and relational ambivalence. J. Pers. Soc. Psychol. 98, 450-468.

Milad, M. R., Pitman, R. K., Ellis, C. B., Gold, A. L., Shin, L. M., Lasko, N. B., Zeidan, M. A., Handwerger, K., Orr, S. P., and Rauch, S. L. (2009). Neurobiological basis of failure to recall extinction memory in posttraumatic stress disorder. Biol. Psychiatry 66, 1075-1082.
Mineka, S. (1985). "Animal models of anxiety-based disorders: their usefulness and limitations," in Anxiety and the Anxiety Disorders, eds A. Tuma and J. D. Maser (Hillsdale, NJ: Erlbaum), 199-244.

Mineka, S. (1988). "A primate model of phobic fears," in Theoretical Foundations of Behavior Therapy, ed. H. Eysenck and I. Martin (New York: Plenum Press), 81-111.

Mineka, S., and Zinbarg, R. (1996). Conditioning and ethological models of anxiety disorders: stress-indynamic-context anxiety models. Perspectives on anxiety, panic, and fear. Nebr. Symp. Motiv. 43, 135-211.

Mineka, S., and Zinbarg, R. (2006). A contemporary learning theory perspective on the etiology of anxiety disorders: it's not what you thought it was. Am. Psychol. 61, 10-26.

Mogg, K., and Bradley, B. P. (2002). Selective orienting of attention to masked threat faces in social anxiety. Behav. Res. Ther. 40, 1403-1414.

Moore, P. S., Whaley, S. E., and Sigman, M. (2004). Interactions between mothers and children: impacts of maternal and child anxiety. J. Abnorm. Child Psychol. 113, 471-476.

Morgane, P. J., Galler, J. R., and Mokler, D. J. (2005). A review of systems and networks of the limbic forebrain/limbic midbrain. Prog. Neurobiol. 75, 143-160.

Murgatroyd, C., and Spengler, D. (2011). Epigenetics of early child development. Front. Psychiatry 2:16. doi: 10.3389/fpsyt.2011.00016

Muris, P., Meesters, C., and Van Den Berg, S. (2003). Internalizing and externalizing problems as correlates of self-reported attachment style and perceived parental rearing in normal adolescents. J. Child Fam. Stud. 12, 171-183.

Murray, L., Creswell, C., and Cooper, P. J. (2009). The development of anxiety disorders in childhood: an integrative review. Psychol. Med. 39, 1413-1423.

Murray, L., Rosnay, M. D., Pearson, J., Bergeron, C., Schofield, E., Lawson, M. R., and Cooper, P. J. (2008). Intergenerational transmission of social anxiety: the role of social referencing processes in infancy. Child Dev. 79, 1049-1064.

Nachmias, M., Gunnar, M., Mangelsdorf, S., Parritz, R. H., and Buss, K. (1996). Behavioral inhibition and stress reactivity: the moderating role of attachment security. Child Dev. $67,508-522$.

National Scientific Council on the Developing Child. (2005). Excessive Stress Disrupts the Architecture of the Developing Brain:
Working Paper \#3. Available at: http://www.developingchild.net

Neumann, I. D. (2008). Brain oxytocin: a key regulator of emotional and social behaviours in both females and males. J. Neuroendocrinol. 20, 858-865.

Nolte, T., Bolling, D.Z., Hudac, C., Fonagy, P., Mayes, L.C., and Pelphrey, K. (under review). Brain mechanisms underlying the impact of attachment-related stress on social cognition.

Norrholm, S. D., and Ressler, K. J. (2009). Genetics of anxiety and trauma-related disorders. Neuroscience 164, 272-287.

Nugent, N. R., Tyrka, A. R., Carpenter, L. L., and Price, L. H. (2011). Geneenvironment interactions: early life stress and risk for depressive and anxiety disorders. Psychopharmacology (Berl.) 214, 175-196.

O'Connor, T. G., Ben-Shlomo, Y., Heron, J., Golding, J., Adams, D. and Glover, V. (2005). Prenatal anxiety predicts individual differences in cortisol in pre-adolescent children. Biol. Psychiatry 58, 211-217.

Oitzl, M. S., Champagne, D. L., van der Veen, R., and de Kloet, E. R. (2010). Brain development under stress: hypotheses of glucocorticoid actions revisited. Neurosci. Biobehav. Rev. 34, 853-866.

Parker, G. (1983). Parental 'affectionless control' as an antecedent to adult depression. A risk factor delineated. Arch. Gen. Psychiatry 40, 956-960.

Pauli-Pott, U., Mertesacker, B., and Beckmann, D. (2004). Predicting the development of infant emotionality from maternal characteristics. Dev Psychopathol. 16, 19-42.

Paulus, M. P., and Stein, M. B. (2006). An insular view of anxiety. Biol. Psychiatry 60, 383-387.

Perez-Edgar, K., Bar-Haim, Y., McDermott, J. M., Gorodetsky, E., Hodgkinson, C. A., Goldman, D., Ernst, M., Pine, D. S., and Fox, N. A. (2010). Variations in the serotonintransporter gene are associated with attention bias patterns to positive and negative emotion faces. Biol. Psychol. 83, 269-271.

Phelps, E. A. (2006). Emotion and cognition: insights from studies of the human amygdala. Ann. Rev. Psychol. 57, 27-53.

Phillips, N. K., Hammen, C. L., Brennan, P. A., Najman, J. M., and Bor, W. (2005). Early adversity and the prospective prediction of depressive and anxiety disorders in adolescents. J. Abnorm. Child Psychiatry 33, 13-24.

Picardi, A., Fagnani, C., Nisticò, L., and Stazi, M. A. (2010). A twin study of attachment style in young adults. J. Pers. doi: 10.1111/j.14676494.2010.00707.x

Pine, D. S. (2007). Research review: a neuroscience framework for pediatric anxiety disorders. J. Child Psychol. Psychiatry 48, 631-648.

Pine, D. S., Cohen, P., Gurley, D., Brook, J., and Ma, Y. (1998). The risk for early-adulthood anxiety and depressive disorders in adolescents with anxiety and depressive disorders. Arch. Gen. Psychiatry 55, 56-64.

Plotsky, P. M., and Meaney, M. J. (1993). Early, postnatal experience alters hypothalamic corticotropinreleasing factor (CRF) mRNA, median eminence CRF content and stress-induced release in adult rats. Mol. Brain Res. 18, 195-200.

Powers, S. I., Pietromonaco, P. R., Gunlicks, M., and Sayer, A. (2006). Dating couples' attachment styles and patterns of cortisol reactivity and recovery in response to a relationship conflict. J. Pers. Soc. Psychol. 90, 613-628.

Prior, M., Smart, D., Sanson, A., and Oberklaid, F. (2000). Does shyinhibited temperament in childhood lead to anxiety problems in adolescence? J. Am. Acad. Child Psychiatry 39, 461-468.

Pruessner, J. C., Champagne, F., Meaney, M. J., and Dagher, A. (2004). Dopamine release in response to a psychological stress in humans and its relationship to early life maternal care: a positron emission tomography study using [11C]raclopride. $J$. Neurosci. 24, 2825-2831.

Pruessner, J. C., Dedovic, K., Pruessner, M., Lord, C., Buss, C., Collins, L., Dagher, A., and Lupien, S. J. (2010). Stress regulation in the central nervous system: evidence from structural and functional neuroimaging studies in human populations. Psychoneuroendocrinology 35, 179-191.

Quirin, M., Gillath, O., Pruessner, J. C., and Eggert, L. D. (2010). Adult attachment insecurity and hippocampal cell density. Soc. Cogn. Affect. Neurosci. 5, 39-47.

Quirin, M., Kuhl, J., and Düsing, R. (2011). Oxytocin buffers cortisol responses to stress in individuals with impaired emotion regulation abilities. Psychoendocrinology 36, 898-904.

Rapee, M., Schniering, C. A., and Hudson, J. L. (2009). Anxiety disorders during childhood and adolescence: origins and treatment. Annu. Rev. Clin. Psychol. 5, 311-341.

Rapee, R. M. (2000). Group treatment of children with anxiety disorders: outcome and predictors of treatment response. Aust. J. Psychol. 52, 125-129. 
Rapee, R. M., and Coplan, R. J. (2010). Conceptual relations between anxiety disorder and fearful temperament. New Dir. Child Adolesc. Dev. 127, 17-31.

Rapee, R. M., and Spence, S. H. (2004). The etiology of social phobia: empirical evidence and an initial model. Clin. Psychol. Rev. 24, 737-767.

Rauch, S. L., Whalen, P. J., Shin, L. M., McInerney, S. C., Macklin, M. L., Lasko, N. B., Orr, S. P., and Pitman, R. K. (2000). Exaggerated amygdala response to masked facial stimuli in posttraumatic stress disorder: a functional MRI study. Biol. Psychiatry 47, 769-776.

Ressler, K. J., and Mayberg, H. S. (2007). Targeting abnormal neural circuits in mood and anxiety disorders: from the laboratory to the clinic. Nat. Neurosci. 10, 1116-1124.

Rickman, M. D., and Davidson, R. J. (1994). Personality and behavior in parents of temperamentally inhibited and uninhibited children. Dev. Psychopathol. 3, 346-354.

Rinne, T., de Kloet, E. R., Wouters, L., Goekoop, J. G., DeRijk, R. $\mathrm{H}$, and van den Brink, W. (2002). Hyperresponsiveness of hypothalamic-pituitaryadrenal axis to combined dexamethasone/corticotropinreleasing hormone challenge in female borderline personality disorder subjects with a history of sustained childhood abuse. Biol. Psychiatry 52, 1102-1112.

Rodrigues, S. M., LeDoux, J. E., and Sapolsky, R. M. (2009). The influence of stress hormones on fear circuitry. Annu. Rev. Neurosci. 32, 289-313.

Roelofs, K., Bakvis, P., Hermans, E. J., van Pelt, J., and van Honk, J. (2007). The effects of social stress and cortisol responses on the preconscious selective attention to social threat. Biol. Psychiatry 75, 1-7.

Roisman, G. I. (2007). The psychophysiology of adult attachment relationships: autonomic reactivity in marital and premarital interactions. Dev. Psychol. 43, 39-53.

Roozendaal, B., McEwen, B. S., and Chattarii, S. (2009). Stress, memory and the amygdala. Nat. Rev. Neurosci. 10, 423-433.

Rosen, J. B., and Schulkin, J. (1998). From normal fear to pathological anxiety. Psychol. Rev. 105, 325-350.

Rosenstein, D. S., and Horowitz, H. A. (1996). Adolescent Attachment and Psychopathology. J. Consult. Clin. Psychol. 64, 244-253.
Rudden, M., Milrod, B., Aronson, A., and Target, M. (2008). "Reflective functioning in panic disorder: clinical observations and research design," in Mentalization, ed. F. N. Busch (New York: Analytic Press), 185-206.

Rutter, M., Moffitt, T. E., and Caspi, A. (2006). Gene-environment interplay and psychopathology: multiple varieties but real effects. J. Child Psychol. Psychiatry 47, 226-261.

Sanson, A., Pedlow, R., Cann, W., Prior, M., and Oberklaid, F. (1996). Shyness ratings: stability and correlates in early childhood. Int. J. Behav. Dev. 19, 705-724.

Sbarra, D. A., and Hazan, C. (2008). Coregulation, dysregulation, self-regulation: an integrative analysis and empirical agenda for understanding adult attachment, separation, loss, and recovery. Pers. Soc. Psychol. Rev. 12, 141-167.

Schiller, D., Monfils, M. H., Raio, C. M., Johnson, D. C., Ledoux, J. E., and Phelps, E. A. (2010). Preventing the return of fear in humans using reconsolidation update mechanisms. Nature 463, 49-53.

Schiller, D., and Phelps, E. A. (2011). Does reconsolidation occur in humans? Front. Behav. Neurosci. 5:24. doi: 10.3389/fnbeh.2011.00024

Schreier, A., Wittchen, H. U., Höfler, M., and Lieb, R. (2008). Anxiety disorders in mothers and their children: prospective longitudinal community study. Br. J. Psychiatry 192, 308-319.

Schulkin, J. (2010). Social allostasis: anticipatory regulation of the internal milieu. Front. Evol. Neurosci. 2:111. doi: 10.3389/fnevo.2010.00111

Seckl, J. R. (2008). Glucocorticoids, developmental "programming" and the risk of affective dysfunction. Prog. Brain Res. 167, 17-34.

Sharp, C., and Fonagy, P. (2008). The parent's capacity to treat the child as a psychological agent: constructs, measures and implications for developmental psychopathology. Soc. Dev. 17, 737-754.

Shaw, S. K., and Dallos, R. (2005). Attachment and adolescent depression: the impact of early attachment experiences. Attach. Hum. Dev. 7, 409-424.

Shekhar, A., Truitt, W., Rainnie, D., and Sajdyk, T. (2005). Role of stress, corticotrophin releasing factor (CRF) and amygdala plasticity in chronic anxiety. Stress 8, 209-219.

Shin, L. M., and Liberzon, I. (2009). The neurocircuitry of fear, stress, and anxiety disorders. Neuropsychopharmacology 35, 169-191.

Simpson, J. A., and Belsky, J. (2008). "Attachment theory within a modern evolutionary framework," in Handbook of Attachment: Theory, Research, and Clinical Applications, 2nd Edn, eds J. Cassidy and P. R. Shaver (New York: Guilford Press), 131-157.

Slade, A. J., Fuerstenberg, S. I., Loeffler, D., Steine, M. N., and Facciotti, D. (2005). A reverse genetic, nontransgenic approach to wheat crop improvement by TILLING. Nat. Biotechnol. 23, 75-81.

Smoller, J. W., Yamaki, L. H., Fagerness, J. A., Biederman, J., Racette, S., Laird, N. M., Kagan, J., Snidman, N., Faraone, S. V., and Hirshfeld-Becker, D. (2005). The corticotropin-releasing hormone gene and behavioral inhibition in children at risk for panic disorder. Biol. Psychiatry 57, 1485-1492.

Sroufe, L. A. (1996). Emotional Development: The Organization of Emotional Life in the Early Years. New York: Cambridge University Press.

Sroufe, L. A., Carlson, E., and Shulman, S. (1993). Individuals in Relationships: Development from Infancy Through Adolescence. Studying Lives Through Time: Personality and Development. Washington, DC: American Psychological Association.

Sroufe, L. A., Fox, N., and Pancake, V. (1983). Attachment and dependency in developmental perspective. Child Dev. 54, 1615-1627.

Stein, M. B., Schork, N. J., and Gelernter, J. (2008). Gene-by-environment (serotonin transporter and childhood maltreatment) interaction for anxiety sensitivity, an intermediate phenotype for anxiety disorders. Neuropsychopharmacology 33, 312-319.

Stein, M. B., Simmons, A. N., Feinstein, J. S., and Paulus, M. P. (2007). Increased amygdala and insula activation during emotion processing in anxiety-prone subjects. Am. J. Psychiatry 164, 318-327.

Stovall-McClough, K., and Cloitre, M. (2006). Unresolved attachment, PTSD, and dissociation in women with childhood abuse histories. J. Consult. Clin. Psychol. 74, 219-228.

Strathearn, L., Fonagy, P., Amico, J., and Montague, R. (2009). Adult attachment predicts maternal brain and oxytocin response to infant cues. Neuropsychopharmacology 34, 2655-2666.

Strathearn, L., Li, J., Fonagy, P., and Montague, R. (2008). What's in a smile? Maternal brain responses to infant facial cues. Pediatrics 122, 40-51.

Suchman, N. E., DeCoste, C., Leigh, D., and Borelli, J. (2010). Reflective functioning in mothers with drug use disorders: implications for dyadic interactions with infants and toddlers. Attach. Hum. Dev. 12, 567-585.

Suveg, C., Sood, E., Barmish, A., Tiwari, S., Hudson, J., and Kendall, P. C. (2008). "I'd rather not talk about it": Emotion parenting in families of children with an anxiety disorder. $J$. Fam. Psychol. 22, 875-884.

Swearingen, E. M. C., and Cohen, L. H. (1985). Life events and psychological distress: a prospective study of young adolescents. Dev. Psychol. 21, 1045-1054.

Tarullo, A. R., and Gunnar, M. R. (2006). Child maltreatment and the developing HPA axis. Horm. Behav. 50, 632-639.

Taylor, S. E., Karlamangla, A. S., Friedman, E. M., and Seeman, T. E. (2011). Early environment affects neuroendocrine regulation in adulthood. Soc. Cogn. Affect. Neurosci. 6, 244-251.

Teicher, M. H., Dumont, N. L., Ito, Y., Vaituzis, C., Giedd, J. N., and Andersen, S. L. (2004). Childhood neglect is associated with reduced corpus callosum area. Biol. Psychiatry 56, 80-85.

Thapar, A., and McGuffin, P. (1995). Are anxiety symptoms in childhood heritable? J. Child Psychol. Psychiatry 36, 439-447.

Tomasello, M., Carpenter, M., Call, J., Behne, T., and Moll, H. (2005). Understanding and sharing intentions: the origins of cultural cognition. Behav. Brain Sci. 28, 675-691; discussion 691-735.

Turner, S. M., Beidel, D. C., and Wolff, P. L. (1996). Is behavioral inhibition related to the anxiety disorders? Clin. Psychol. Rev. 16, 157-172.

Urry, H. L., van Reekum, C. M., Johnstone, T., Kalin, N. H., Thurow, M. E., Schaefer, H. S., Jackson, C. A., Frye, C. J., Greischar, L. L., Alexander, A. L., and Davidson, R. J. (2006). Amygdala and ventromedial prefrontal cortex are inversely coupled during regulation of negative affect and predict the diurnal pattern of cortisol secretion among older adults. J. Neurosci. 26, 4415-4425.

Van den Bergh, B. R. H., and Marcoen, A. (2004). High antenatal maternal anxiety is related to ADHD symptoms, externalizing problems and anxiety in 8/9-year-olds. Child Dev. 75, 1085-1097. 
Van den Bergh, B. R. H., Van Calster, B., Smits, T., Van Huffel, S., and Lagae, L. (2008). Antenatal maternal anxiety is related to HPA-axis dysregulation and self-reported depressive symptoms in adolescence: a prospective study on the fetal origins of depressed mood. Neuropsychopharmacology 33, 536-545.

van den Heuvel, O. A., Veltman, D. J., Groenewegen, H. J., Witter, M. P., Merkelbach, J., Cath, D. C., van Balkom, A. J., van Oppen, P., and van Dyck, R. (2005). Disorderspecific neuroanatomical correlates of attentional bias in obsessivecompulsive disorder, panic disorder, and hypochondriasis. Arch. Gen. Psychiatry 62, 922-933.

van Ijzendoorn, M. H., Caspers, K., Bakermans-Kranenburg, M. J., Beach, S. R., and Philibert, R. (2010). Methylation matters: interaction between methylation density and serotonin transporter genotype predicts unresolved loss or trauma. Biol. Psychiatry 68, 405-407.

Vasey, M. W., and Dadds, M. R. (eds). (2001). The Developmental Psychopathology of Anxiety. New York: Oxford University Press, 386-406.

Vaughn, B. E., and Bost, K. K. (1999). "Attachment and temperament: redundant, independent, or interacting influences on interpersonal adaptation and personality development?" in Hand-book of Attachment: Theory, Research, and Clinical Applications, eds J. Cassidy and P. R. Shaver (New York: Guilford status), 198-225.

Vaughn, B. E., Bost, K. K., and van Ijzendoorn, M. H. (2008). "Attachment and temperament: additive and interactive influences on behavior, affect, and cognition during infancy and childhood," in Handbook of Attachment: Theory, Research, and Clinical Applications, 2nd Edn, eds J. Cassidy and P. R. Shaver (New York: Guilford Press), 192-216.

Vrticka, P., Andersson, F., Grandjean, D., Sander, D., and Vuilleumier, P. (2008). Individual attachment style modulates human amygdala and striatum activation during social appraisal. PLoS ONE 3, e2868. doi: 10.1371/journal.pone.0002868

Vuilleumier, P., Armony, J. L., Driver, J., and Dolan, R. J. (2001). Effects of attention and emotion on face processing in the human brain: an event related fMRI study. Neuron 30, 829-841.

Warren, S. L., Huston, L., Egeland, B., and Sroufe, L. A. (1997). Child and adolescent anxiety disorders and early attachment. J. Am. Acad. Child Psychiatry 36, 637-644.

Warren, S. L., and Simmens, S. J. (2005). Predicting toddler anxiety/depressive symptoms: effects of caregiver sensitivity on temperamentally vulnerable children. Inf. Mental Health J. 26, 40-55.

Weaver, I. C., Cervoni, N., Champagne, F. A., D'Alessio, A. C., Sharma, S., Seckl, J. R., Dymov, S., Szyf, M., and Meaney, M. J. (2004). Epigenetic programming by maternal behaviour. Nat. Neurosci. 7, 847-854.

Weinfield, N. S., Sroufe, L. A., Egeland, B., and Carlson, E. A. (1999). "The nature of individual differences in infant-caregiver attachment," in Handbook of Attachment: Theory, Research, and Clinical Applications, eds J. Cassidy and P. R. Shaver (New York: Guilford Press), 68-88.

Weinstock, M., Matlina, E., Maor, G. I., Rosen, H., and McEwen, B. S. (1992). Prenatal stress selectively alters the reactivity of the hypothalamic-pituitary adrenal system in the female rat. Brain Res. 595, 195-200.

Wellman, C. L. (2001). Dendritic reorganization in pyramidal neurons in medial prefrontal cortex after chronic corticosterone administration. J. Neurobiol. 49, 245-253.

Wells, A. (1997). Cognitive Therapy of Anxiety Disorders: A Practice Manual and Conceptual Guide. Chichester: Wiley.

Whaley, S. E., Pinto, A., and Sigman, M. (1999). Characterizing interactions between anxious mothers and their children. J. Consult. Clin. Psychol. 67 826-836.

Windle, M., and Lerner, R. M. (1986). Reassessing the dimensions of temperamental individuality across the lifespan: the revised dimensions of temperament survey (DOTS-R). $J$. Adolesc. Res. 1, 213-230.

Wittchen, H. U., Kessler, R. C., Pfister, H., Höfler, M., and Lieb, R. (2000). Why do people with anxiety disorders become depressed? A prospective-longitudinal community study. Acta Psychiatr. Scand. 102, 14-23.

Wood, J. J., McLeod, B. D., Sigman, M., Hwang, W., and Chu, B. C. (2003). Parenting and childhood anxiety: theory, empirical findings, and future directions. J. Child Psychol. Psychiatry 44, 134-151.

Zhang, X., Li, T., and Zhou, X. (2008). Brain responses to facial expressions by adults with different attachment-orientations. $\mathrm{Neu}$ roreport $19,437-441$.

Zilber, A., Goldstein, A., and Mikulincer, M. (2007). Adult attachment orientations and the processing of emotional pictures - ERP correlates. Pers. Indiv. Differ. 43, 1898-1907.

Zimmerman, M., and Chelminski, I. (2003).Generalized anxiety disorder in patients with major depression: is DSM-IV's hierarchy correct? Am. J. Psychiatry 160, 504-512.

Conflict of Interest Statement: The authors declare that the research was conducted in the absence of any commercial or financial relationships that could be construed as a potential conflict of interest.

Received: 01 June 2011; paper pending published: 02 July 2011; accepted: 14 August 2011; published online: 21 September 2011.

Citation: Nolte T, Guiney J, Fonagy P, Mayes LC and Luyten P (2011) Interpersonal stress regulation and the development of anxiety disorders: an attachment-based developmental framework. Front. Behav. Neurosci. 5:55. doi: 10.3389/fnbeh.2011.00055

Copyright (c) 2011 Nolte, Guiney, Fonagy, Mayes and Luyten. This is an openaccess article subject to a non-exclusive license between the authors and Frontiers Media SA, which permits use, distribution and reproduction in other forums, provided the original authors and source are credited and other Frontiers conditions are complied with. 